\title{
Evaluating DNAPL Source and Migration Zones: M-Area Settling Basin and the Western Sector of A/M Area, Savannah River Site (U).
}

June 15,2001 
This document was prepared in conjunction with work accomplished under Contract No.

DE-AC09-96SR18500 with the U.S. Department of Energy.

\section{DISCLAIMER}

This report was prepared as an account of work sponsored by an agency of the United States Government. Neither the United States Government nor any agency thereof, nor any of their employees, makes any warranty, express or implied, or assumes any legal liability or responsibility for the accuracy, completeness, or usefulness of any information, apparatus, product or process disclosed, or represents that its use would not infringe privately owned rights. Reference herein to any specific commercial product, process or service by trade name, trademark, manufacturer, or otherwise does not necessarily constitute or imply its endorsement, recommendation, or favoring by the United States Government or any agency

thereof. The views and opinions of authors expressed herein do not necessarily state or reflect those of the United States Government or any agency thereof.

This report has been reproduced directly from the best available copy.

Available for sale to the public, in paper, from: U.S. Department of Commerce, National Technical Information Service, 5285 Port Royal Road, Springfield, VA 22161, phone: (800)

553-6847, fax: (703) 605-6900, email: orders@ntis.fedworld.gov online ordering: http://www.ntis.gov/ordering.htm

Available electronically at http://www.doe.gov/bridge

Available for a processing fee to U.S. Department of Energy and its contractors, in paper, from: U.S. Department of Energy, Office of Scientific and Technical Information, P.O. Box 62, Oak Ridge, TN 37831-0062, phone: (865 ) 576-8401, fax: (865) 576-5728, email: reports@ adonis.osti.gov 


\title{
Evaluating DNAPL Source and Migration Zones: M-Area Settling Basin and the Western Sector of A/M Area, Savannah River Site (U).
}

June 15, 2001

Dennis G. Jackson, Jr.

Brian B. Looney

With contributions by:

\author{
Martha C. Thompson \\ Thomas F. Kmetz \\ James J. Kupar \\ Environmental Restoration Division, Savannah River Site \\ David C. Noffsinger \\ Site Geotechnical Services \\ Karen M. Vangelas \\ Savannah River Technology Center, Savannah River Site
}

Prepared By:

Dennis G. Jackson Jr.

Date 
WSRC-TR-2001-00198

\section{Executive Summary:}

Detailed characterization data collected near the M Area Settling Basin provides a technical basis for understanding and addressing DNAPL at this site. The data and interpretation confirm general DNAPL migration and accumulation behaviors, as well as delineate specific regions that are most important to cleanup using source remediation methods such as steam flushing. Key elements in the interpretation included the use of three-dimensional imaging, screening criteria to consolidate data from different subsurface sampling media (solid, liquid and gas), and relating the real-world data to a simple conceptual model of expected behaviors. To support the work, we developed an informative new type of figure that integrates and posts the data in three dimensions along with information on geology on a single page. Based on the results, various source clean up scenarios were developed, ranging from a minimum volume scenario to a highly conservative maximum volume scenario. A strategic scenario developed by an interdisciplinary and interdepartmental technical team balanced the various factors in the end-case scenarios. The delineated boundaries of the strategic scenario generated a treatment volume of 294,090 cubic yards and provides a starting point for planning future DNAPL source remediation at this site.

The minimum volume scenario encompasses only the portion of the subsurface with confirmed (observed or certain) DNAPL. The maximum volume scenario encompasses most of the subsurface region with possible DNAPL. The strategic case balances these end casesincorporating most of the subsurface volumes with suspect DNAPL and key areas that are designated as possible DNAPL migration or accumulation zones. Other important balancing criteria incorporated into the strategic case include: a) the effectiveness/efficiency of the subject steam remediation approach to address the observed DNAPL geometry in each portion of the subsurface, and b) related observations such as time histories of monitoring well or remediation well concentration. Observations from monitoring and recovery wells were critical in determining the horizontal extent of the treatment zone. Based on historical observations pump \& treat operations at RWM-8 an additional 5-years of post-remediation pump \& treat operation will be required using the strategic scenario proposed. Pre- and post remediation monitoring at MSB-10C, 12B, 12C, 17B, and 76C will be necessary to assess the effectiveness of any remediation associated with the Western Sector. 
WSRC-TR-2001-00198

\section{Table of Contents:}





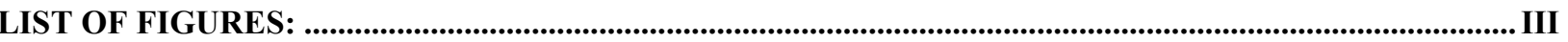



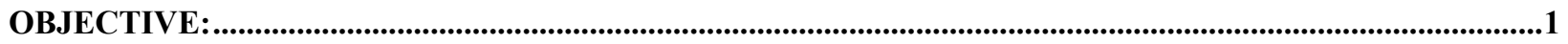



SUMMARY OF M AREA SETTLING BASIN HISTORY: ............................................................................2

OVERALL A/M AREA GROUNDWATER REMEDIATION STRATEGY: ..................................................5

CONCEPTUAL IDENTIFICATION OF SOURCE ZONE REMEDIATION TARGETS: .................................9

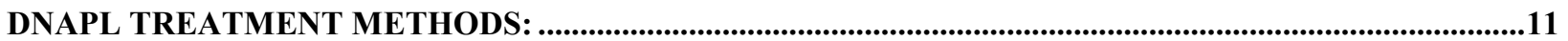

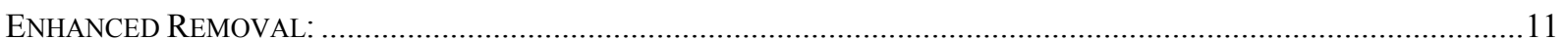

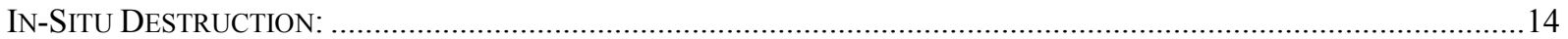

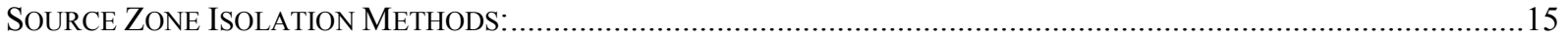

RELEVANT A/M-AREA DNAPL CHARACTERIZATION DATA:.........................................................18

IDENTIFICATION OF DNAPL TARGET TREATMENT ZONES: ..........................................................31

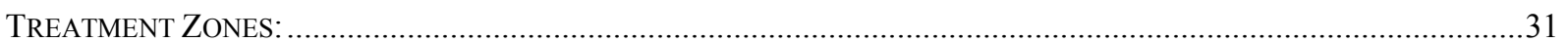





APPENDIX A: BRIEF HISTORY OF A/M AREA DNAPL CHARACTERIZATION ..................................43 
WSRC-TR-2001-00198

\section{List of Figures:}

FIGURE 1: PLAN VIEW MAP OF A/M AREA SHOWING THE LOCATIONS OF VARIOUS FORMER PROCESS FACILITIES AND

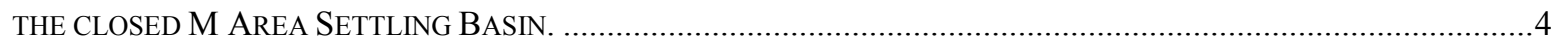

FIGURE 2 CONCEPTUALIZATION DEPICTING THE NATURE AND EXTENT OF A CONTAMINATED FACILITY .....................

FIGURE 3: CHARACTERIZATION AND REMEDIATION TECHNIQUES FOR A CONTAMINATED FACILITY..........................7

Figure 4: ANATOMY OF THE CHLORINATED SOLVENT PluME IN A/M AREA OF THE SAVANNAH RIVER SiTE

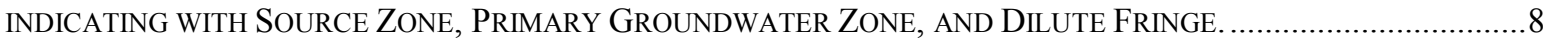

FIGURE 5: EXPECTED DISTRIBUTION OF DNAPL BENEATH A SITE SUCH AS THE M AREA BASIN IN LAYERED COASTAL

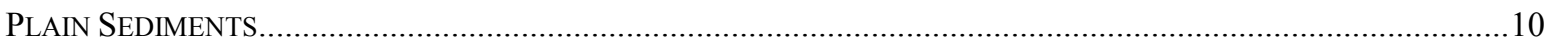



FIGURE 7: HISTORICAL PLAN VIEW TWO-DIMENSIONAL POSTING MAP SHOWING THE LOCATION OF GROUNDWATER

MONITORING WELLS EXCEEDING 1\% OF DNAPL SOLUBILITY (JACKSON, PAYNE ET AL. 1996)....................22

FIGURE 8: DNAPL RELATED CHARACTERIZATION DATA THROUGHOUT A/M AREA.............................................23

FIGURE 9: THREE-DIMENSIONAL DISTRIBITION OF DNAPL CHARACTERIZATION DATA ASSOCIATED WITH WESTERN

SECTOR. (NOTE THAT THE M-AREA AQUIFER AND GREEN ClAy UNITS ARE SHOWN SEMI-TRANSPARENT.).....24

FIGURE 10: EXTENT OF WESTERN SECTOR SOURCE AND MIGRATION SHOWING MAJOR LITHOGRAPHIC UNITS

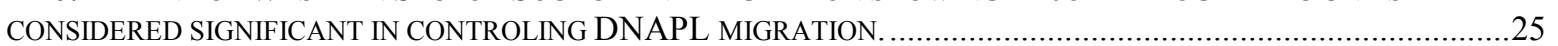

FIGURE 11: LOCATION AND DISTRIBUTION OF DNAPL RELATED CHARACTERIZATION DATA IN ASSOCIATED WITH

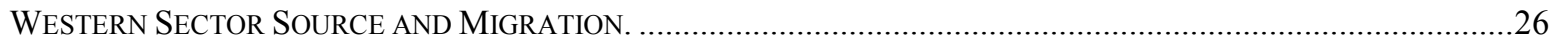

FIGURE 12: LOCATION AND DISTRIBIUTION OF DNAPL RELATED CHARACTERIZATION DATA ASSOCIATED WITH

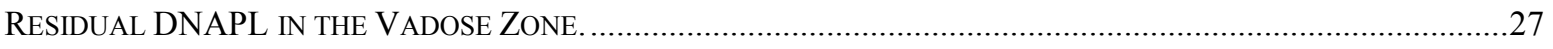

FIGURE 13: LOCATION AND DISTRIBIUTION OF DNAPL RELATED CHARACTERIZATION DATA ASSOCIATED WITH

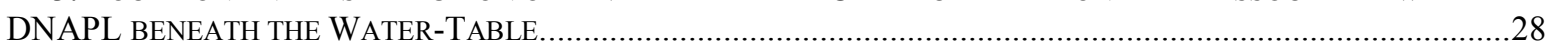

FIGURE 14: DNAPL RELATED CHARACTERIZATION DATA IN THE VADOSE ZONE, M-AREA AQUIFER, AND LOST-

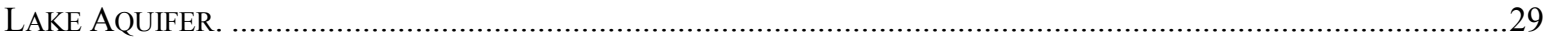

FIGURE 15: LOCATION AND DISTRIBIUTION OF DNAPL RELATED CHARACTERIZATION DATA ASSOCIATED WITH THE

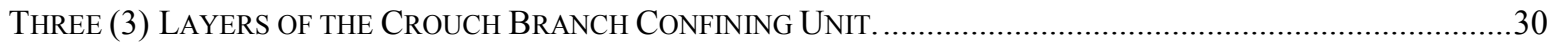

FIGURE 16: HORIZONTAL EXTENT OF PROPOSED TREATMENT ZONES FOR DNAPL SPECIFIC REMEDIAITON

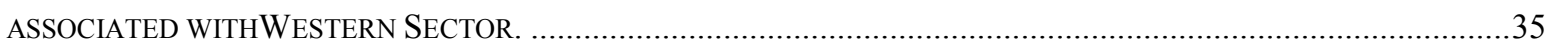

FIGURE 17: TRICHLOROETHYLENE CONCENTRATIONS FROM RWM 1, RWM 8, AND RWM 10 …..........................36

FIGURE 18: TETRACHLOROETHYLENE CONCENTRATIONS FROM RWM 1, RWM 8, AND RWM 10......................36

FigURE 19: HiSTORICAL TRICHLOROETHYLENE CONCENTRATIONS ALONG DNAPL MigRATION PATH....................37

FIGURE 20: HiSTORICAL TETRACHLOROETHYLENE CONCENTRATIONS ALONG DNAPL MIGRATION PATH................37

FIGURE 21: OBSERVED AND SIMULATED TRICHLOROETHYLENE AND TETRACHLOROETHYLENE CONCENTRATIONS FOR RECOVERY WELL RWM-8. 


\section{List of Tables:}

TABLE 1: SUMMARY OF COMMERICAL OR NEAR COMMERCIAL DNAPL SOURCE REMEDIATION METHODS...............16

TABLE 2: DNAPL SCREENING CATEGORIES AND NUMERICAL SCREENING CRITERIA APPLIED .................................19

TABLE 3: VOLUME ESTIMATES FOR EACH OF THE PROPOSED TREATMENT AREAS ILLUSTRATED IN FIGURE 6..........39

TABLE 4: TREATMENT ZONES AND STRATEGRAPHIC INTERVALS ASSOCIATED WITH THE MAXIMUM VOLUME



TABLE 5: TREATMENT ZONES AND STRATEGRAPHIC INTERVALS ASSOCIATED WITH THE MINIMUM VOLUME

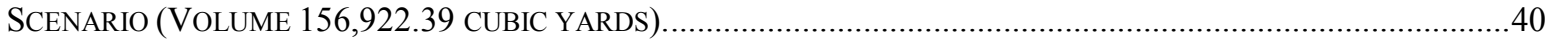

TABLE 6: TREATMENT ZONES AND STRATEGRAPHIC INTERVALS ASSOCIATED WITH THE STRATEGIC VOLUME




WSRC-TR-2001-00198

\section{Objective:}

The objective of this investigation is to critically evaluate previous characterization and remediation data to determine the current extent and distribution of DNAPL associated with releases at the M-Area Basin within A/M Area. The primary objective of the effort is to develop an approximate recommendation for the target treatment location and volume near the M Area Settling Basin. Through this analysis the final objective is to identify those subsurface regions having specific geometry and character necessary to cost-effectively deploy DNAPL specific remediation alternatives.

\section{Introduction:}

Discharges and disposals of industrial solvents in the vicinity of the former metals fabrication facilities (the A/M Area) at the Savannah River Site (SRS) have contaminated soil and groundwater. This contamination is currently being cleaned up using a phased approach that emphasizes the need for aggressive technologies to remediate the most contaminated zone and less aggressive technologies to address the more dilute regions of contamination. A critical component in this strategy is the enhanced removal and/or destruction of the large quantities of undissolved solvents immediately near and associated with the original release locations. When solvents of this type are present in the subsurface they are referred to as DNAPLs (dense nonaqueous phase liquids) and serve as a long-term source for groundwater contamination. (Cohen and Mercer 1993; Pankow and Cherry 1996) Under conditions such as those in the A/M Area, if these solvents are left within the subsurface, they will slowly dissolve over hundreds of years and serve as a long-term source of groundwater contamination within A/M Area. (Jackson et al. 1996)

Locating DNAPL and subsequently selecting and implementing a targeted-cost-effective remediation strategy is challenging. In both the selection and implementation arenas, SRS has supported and benefited from the significant DNAPL related technology advances over the past 15 years. For example, the DNAPL characterization toolbox (Rossabi et al. 2000), and many of the underlying methods, were developed and tested at SRS and are now in general use throughout the United States. Based on the various DNAPL characterization efforts applied in the A/M Area, several pilot and full scale DNAPL treatment systems have been deployed. Notably, SRS has successfully implemented two large-scale DNAPL specific treatments:

1. an in-situ chemical destruction method based on Fenton's chemistry was applied to an isolated DNAPL accumulation zone near the M Area Settling Basin (Jerome et al. 1997),

2. an ongoing steam based source zone treatment at the former $321 \mathrm{M}$ solvent storage tank (currently underway).

Performance monitoring of these two successful treatment systems indicate that each is applicable to specific A/M Area DNAPL migration and accumulation scenarios. In particular, the data indicate that steam based remediation is well suited to DNAPL immediately beneath and adjacent to large former DNAPL source areas. Within the A/M Area these areas would include the solvent storage tank (DNAPL remediation completed), the M-Area Settling Basin, and the A014 Outfall. The magnitude and extent of DNAPL released at each of these source areas have been extensively documented throughout the A/M Area corrective action program (Marine and Bledose 1984; Looney et al. 1992; Jackson, Payne et al. 1996; Jarosch et al. 1997; Jackson et al. 1999). 
In-situ chemical destruction methods such as those based on Fenton's chemistry, and chemical injection methods, such as enhanced mobilization using surfactants and cosolvents, appear most promising for clearly-defined DNAPL accumulation areas that are relatively small, and/or relatively thin and deep in the aquifer. DNAPL in this configuration was effectively identified and targeted using Fenton's based chemistry. (Jerome, Riha et al. 1997; Jerome et al. 1998) Based on these observations and experiences, SRS has selected and is currently planning to implement steam based cleanup for major portion of the residual DNAPL associated with the M Area Settling Basin followed by implementation at the A-014 Outfall.

To assist in developing a preliminary technical basis for deploying a large-scale source zone DNAPL treatment(s), we summarize background information related to remediation of soil and groundwater in the $\mathrm{A} / \mathrm{M}$ Area and then present the pertinent DNAPL related data. The primary objective of the effort is to develop an approximate recommendation for the target treatment location and volume near the M Area Settling Basin. To support this objective, we also compare and contrast the characteristics of steam based clean up and current/promising alternatives to help define the most appropriate steam treatment zone - i.e., the DNAPL contaminated area where the contaminant distribution is best matched to the characteristics of the clean-up method.

\section{Summary of M Area Settling Basin History:}

Process wastewater discharged from buildings 313-M, 320-M and 321-M to the M-Area Settling Basin from 1958 to 1985. (Marine and Bledose 1984) The M-Area Settling Basin (see Figure 1) was an eight million gallon unlined surface impoundment designed to settle solids (primarily nickel and aluminum hydroxides) discharged from fuel and target fabrication processes, to sorb dissolved metals to the underlying soil, and to allow volatilization/infiltration of organic solvents. The M-Area waste stream contained metals (nickel, aluminum, uranium, lead), acids, caustics, and solvents from aluminum-forming and electroplating processes. (Colven et al. 1984) Under the RCRA Hazardous Waste Listings promulgated in 1980, the waste stream was classified as F006-electroplating waste (Looney, Rossabi et al. 1992). It is estimated that 2 million pounds of chlorinated solvents (trichloroethylene (TCE), tetrachloroethylene (PCE), and 111-trichloroethane (TCA)) were released to the M-Area Settling Basin (Marine and Bledose 1984). When released to the subsurface, these solvents, and similar compounds, are commonly classified as dense nonaqueous phase liquids, or DNAPLs. (Pankow and Cherry 1996) These solvents are denser than "water" and their discharges to the M-Area Settling Basin were made periodically in batches primarily associated with disposal of the "bottoms" from the vapor degreasers located in the 300-Area process facilities. As a result of their density, most of the solvent that were released to the former basin are expected to have occupied the deepest portion of the basin and would have entered the subsurface. Importantly, except for the periodic solvent discharges, process wastes discharged to the basin were typically either 1) high-pH solutions that contained high dissolved salt concentrations and flocculant precipitates, or 2) relatively clean water such as non-contact cooling water. As a result, the former basin was permanently stratified along a chemocline. Relatively clean water occupied the upper portion of the water column while the lower portion of the water column was comprised of an alkaline dense aqueous phase liquid (DAPL) (along with the periodic solvent discharges). (Hollod 1982; Hollod et al. 1982; Colven, Pickett et al. 1984) Prior to basin closure, most of the dense aqueous and nonaqueous phases would have entered the subsurface. The overlying clean water would have served as a cap minimizing solvent volatilization. Overflow from the basin consisted primarily of the clean upper layer and entrained metal floc. 
SRS prepared a closure plan for the M Area Settling Basin in 1984. (Colven, Pickett et al. 1984) This plan described the closure of the M-Area Settling Basin by placement of a RCRA cap. The closure plan was submitted and approved by SCDHEC in 1987. Basin closure activities began in 1988 with completion in 1990. The closure plan included the dewatering and treatment of liquid within the basin, followed by cement stabilization of remaining sludge. The remaining sludge contained the majority of the inorganic contaminants. Following stabilizization, the sludge was mixed with cement and placed back into the basin. A low-permeability cap was then placed atop this material (Colven, Pickett et al. 1984). In 1985 SRS submitted a RCRA Part B Permit Application to include M-Area HWMF post-closure maintenance, groundwater monitoring, and corrective-action systems. SCDHEC approved and issued the Part B permit in September 1987 with periodic renewal required (Looney, Rossabi et al. 1992).

Current Part B Corrective Actions for the vadose zone and groundwater in the immediate vicinity of the M Area Settling Basin include: groundwater extraction and treatment, soil vapor extraction, and pilot deployment of in-situ oxidation (using Fenton's Reagent). To date, the total contaminant mass removal from the various pilot scale, research and full scale corrective actions at the M- Area Settling Basin over 120,000 pounds.

A large number of baseline and innovative characterization tools have been used to support the clean-up activities. These tools, their interpretation, and specific results have been documented in a series of reports. The characterization and monitoring data are also the basis for the scoping evaluation documented herein. A key finding from the various studies is documentation that structural features, such as a trough on the surface of the "green clay," control the migration and distribution of DNAPL below the water table. In particular, these geologic controls distribute the DNAPL in a relatively narrow migration path towards the west. As a result, the basin is considered as a long-term source of solvent contamination to the "western sector" of the A/M Area groundwater corrective action. An integrated clean up approach will require addressing any residual DNAPL associated with the former basin in combination with actions targeted at the intermediate dissolved concentration plume and the low concentration fringe. 




Figure 1: Plan view map of A/M Area showing the locations of various former process facilities and the closed M Area Settling Basin. 


\section{Overall A/M Area Groundwater Remediation Strategy:}

Figure 2 provides a conceptual plan view diagram of a contaminated site that has impacted the underlying soil and groundwater. The three ovals - the source zone, the primary contaminant plume, and the dilute fringe - represent different portions of the impacted environment that each has a different character. The source zone contains significant contamination in concentrated and hazardous forms - for organic solvent contamination, this is the area containing DNAPL. The second oval, the primary contaminant plume, is comprised of contaminated groundwater or vapor than carries pollutants at lower levels, but levels that still represent a potentially significant present or future hazard. The third oval, the dilute fringe, contains contamination at relatively low concentrations, but in large volumes of water.

Efficient and effective environmental clean up requires matching the character of the clean-up and stabilization methods to the character of the target zone of contamination. Thus, aggressive and relatively expensive methods are often appropriate for the source zone, classical pump-andtreat methods are often good for the primary contamination zone, and various methods based on natural processes are often best for the dilute fringe. Figure 2 identifies several example technologies that are appropriate for each of the ovals.

In Figure 3 the conceptual model is extended by identifying the cost basis associated with typical clean up technologies. In the source zone, destruction or enhanced removal methods are normally priced on the basis of volume of soil or amount of contaminant in the treatment zone ( $\$$ per cubic yard, $\$$ per pound and the like). The reference source zone technologies require aggressive access and subsequent use of targeted energy or chemical reagents. Prudent implementation of aggressive methods requires care to focus energy or reagent to areas where they are needed. Equally important, however, is a desire to minimize potential undesired negative impacts (wasting energy, harming microbiological populations, etc.) associated with using aggressive remedies on regions without source level contamination.

In the primary contaminant plume, treatment technologies are normally priced in terms of the amount of water (or vapor) treated $\left(\$ / \mathrm{m}^{3}, \$ / 1000\right.$ gallons and the like). Thus, the goal of characterization is to define the flow directions and general plume structure to allow the most contaminant to be treated in the fewest "gallons". Figure 4 illustrates an important-final extension to the simplified conceptual model. This diagram of the primary contaminant plume at the SRS metals fuel and target fabrication facility (M Area) shows that contamination moves in response to many factors - contaminant release location and type, geology, sources and discharges of water, and many others. The resulting contaminated soil and groundwater zone occupies a complicated three-dimensional shape rather than the simplified ovals as shown in Figure 2 and Figure 3 . This complexity must be recognized when developing and implementing technologies for both characterization and clean up of the primary contaminant plume.

The dilute fringe contains low concentrations of contamination in large volumes of water. Thus, the best technologies for this zone are those that are priced on the basis of time ( $\$ /$ year and the like). To be successful, these technologies must rely on natural-sustainable-measurable processes. This class of technology has gained recent regulatory support under the terminology "monitored natural attenuation". For the dilute fringe, technology selection is biased toward understanding the contaminant destruction and stabilization capabilities of native species and natural populations. A second step is identifying engineering interventions, if needed, to maximize the performance and to assure that the attenuation process will operate for extended 
periods. A critical requirement for these technologies development of logical and cost-effective monitoring strategies.

The three zones depicted in Figure 2 are present at contaminated sites of all sizes. At a gas station, the entire contaminated zone - all three ovals - might occupy a portion of a city block. At a large industrial facility like the A/M Area at SRS, the contaminated zone extends over a few square miles. The size of a problem impacts how distinct the actions to address the different zones need to be. For the Western Sector of the A/M Area Groundwater Corrective Action, we believe that successful clean up will require distinct and well documented actions to address the various portions of the plume and that addressing remaining DNAPL from the former M Area Settling Basin is a critical step. Time is also a factor. Concentrations change as cleanup progresses, so that dilute fringe technologies become appropriate for polishing areas that were formerly at higher concentrations. This phased progression to clean-up will be used as source areas are converted to dissolved plumes and then to natural attenuation actions. 


\section{Anatomy of a Contaminated Site}

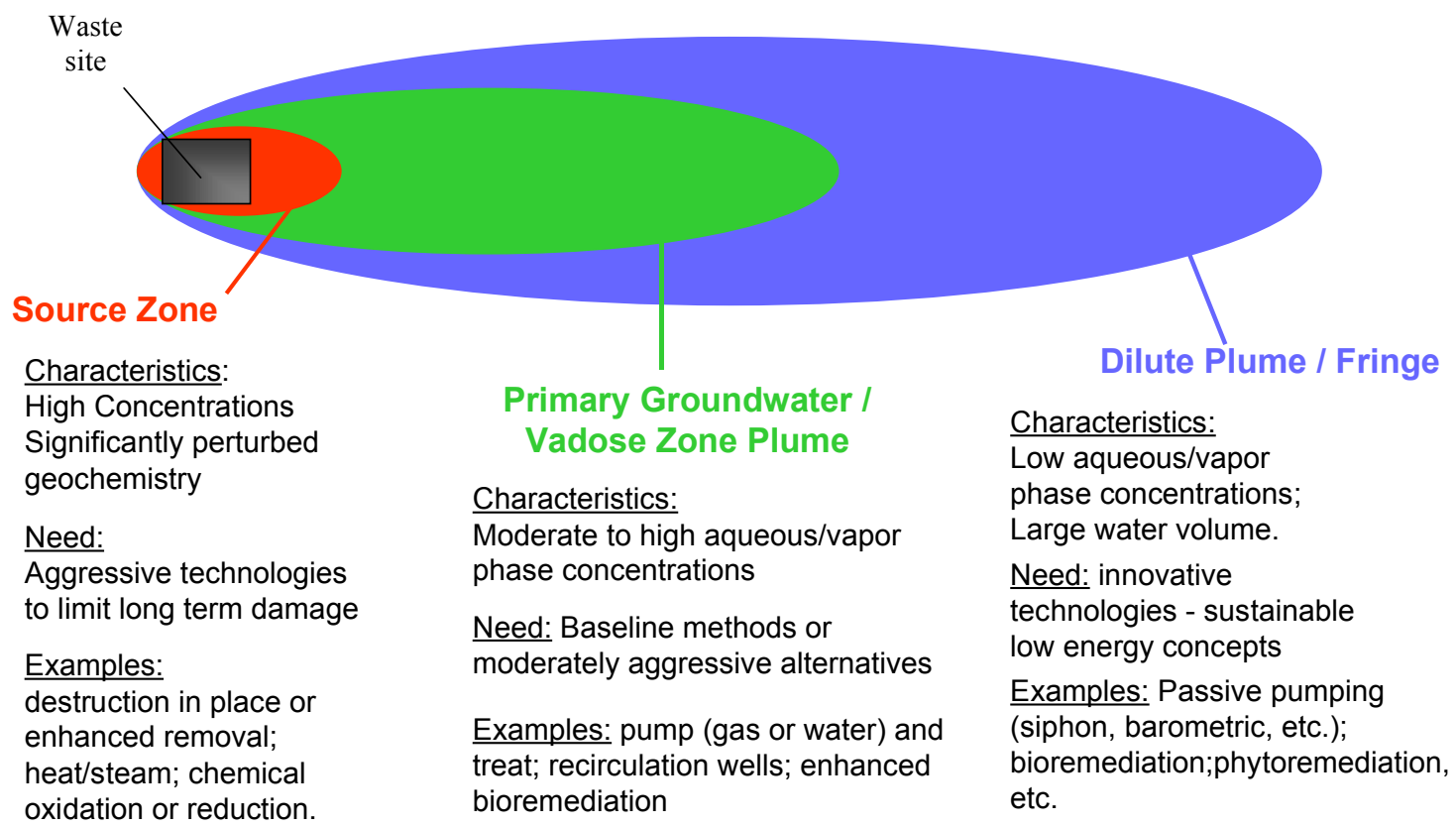

Figure 2 Conceptualization Depicting the Nature and Extent of a Contaminated Facility.

\section{Diagnosing and Treating a Contaminated Site}

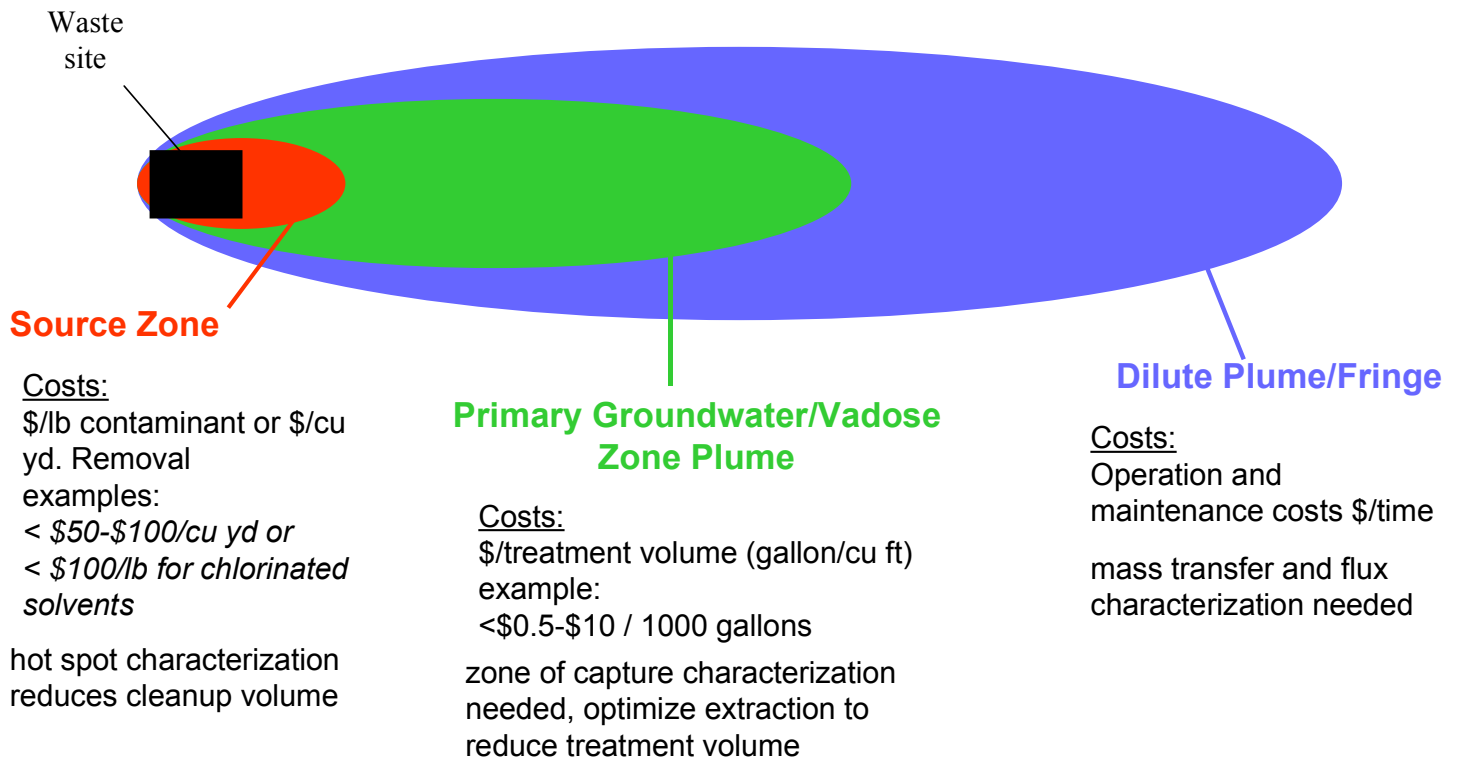

Figure 3: Characterization and Remediation Techniques for a Contaminated Facility. 




Figure 4: Anatomy of the Chlorinated Solvent Plume in A/M Area of the Savannah River Site indicating with Source Zone, Primary Groundwater Zone, and Dilute Fringe. 
WSRC-TR-2001-00198

\section{Conceptual Identification of Source Zone Remediation Targets:}

A conceptual model illustrating the movement and expected subsurface distribution for the DNAPL source beneath a facility such as the M-Area Settling Basin is presented in Figure 5 . In this figure, the expected DNAPL behaviors and resulting distribution associated with geological conditions such as those at the basin are depicted. As the DNAPL migrates in the subsurface, local heterogeneities of the sediments influence DNAPL movement and accumulation. DNAPL continues to migrate given a sufficient driving force in the form of continued disposal of solvent wastes. When the DNAPL source is exhausted and the driving force for movement removed, the DNAPL mass in the subsurface will reach a stable configuration based upon the applied gravitational, hydrodynamic, and capillary forces. At this stage, residual DNAPL remains in the pore throats along the migration path and in accumulation areas controlled by geological structure. In the vadose zone, DNAPL moves downward due to gravity. Above the water table, DNAPL may be the wetting phase, and thus, residual DNAPL is held by capillary forces in the pores of layered fine-grained sediments typical of the Atlantic Coastal Plain. Below the water table, DNAPL tends to move vertically in narrow "fingers" and then accumulate in thin laterally extensive layers at the base of the affected aquifer. In contrast to the vadose zone, DNAPL accumulation below the water table is in coarse-grained sediments immediately above clayey intervals. Once the source is removed, residual DNAPL is left throughout the entire migration pathway due to "snap-off" in pore throats as the DNAPL front moves away. Because of the relatively low solubility of DNAPL solvents, all of these types of residual and accumulated source material in the subsurface represent a large fraction of the original mass released at most sites. As a result, the DNAPL represents the primary long-term source for groundwater contamination over an extended period (circa 100s of years). (Jackson, Payne et al. 1996)

When DNAPL has a high application rate over a small area, such as the M Area Settling Basin, DNAPL will penetrate down into the water table. In these cases, the DNAPL obtains a large enough continuous (organic phase) head to penetrate the capillary fringe. Once the capillary fringe is penetrated the DNAPL flow is primarily controlled by the structure of any capillary barriers (clays and other fine-grained layers). Immediately beneath the source, DNAPL moves vertically though the vadose zone and shallow groundwater (Eigure 6, Zone I and Zone IIa). As DNAPL moves away from the source, it forms a thin "bottom dwelling" interval that moves in response to the physical slope on the clay surface (Zone IIIa) and will penetrate any discontinuities in the clay interval. Each major penetration location will result in formation of a new area of vertical migration (Zone $\mathrm{IIb}$ ) and a new thin bottom dwelling migration interval (Zone IIIb). Different DNAPL remediation methods will have advantages and disadvantages for the various DNAPL scenarios in the target zones. These are summarized in the next section to support identification of the appropriate target(s) for planned near term DNAPL remediation activities. Based on the characteristics of the potential and proposed remediation methods, and available history/data from the M Area Basin, the approximate location and elevation of the target treatment zones (Ia, Ib, etc.) will be identified. 




Figure 5: Expected distribution of DNAPL beneath a site such as the M Area Basin in layered Coastal Plain Sediments



Figure 6: DNAPL remediation target zones of different character and geometry 
WSRC-TR-2001-00198

\section{DNAPL Treatment Methods:}

A variety of approaches and methods have been proposed and tested for treatment of DNAPL contaminated soil and groundwater. As described below, each approach has strengths and weaknesses. Effective and prudent use of the technologies requires that the selection process be guided by matching the strengths, or unique advantages, of a method to the characteristics of the site, while minimizing any problems associated with the methods weaknesses. Thus, the technology selection should strongly consider site characteristics such as geology and the location and distribution of the contaminant. Similarly, while the selected steam based clean up systems are clearly appropriate for the major portion of the residual DNAPL underlying and adjacent to the M Area Settling Basin, the listed factors provide important constraints to help develop the technical basis for where and how the treatment is performed.

When applied to DNAPL sources, the baseline technologies (groundwater pump and treat with soil vapor extraction), represent a possible, but extended time frame strategy. Diffusion of DNAPL vapor from fine grained sediments in the vadose zone and slow dissolution of trapped DNAPL source in the shallow groundwater results in long periods of operation to meet permitted clean-up levels. Previous investigations (Jackson, Payne et al. 1996) estimated that cleaning up the primary A/M Area sources (M Area Settling Basin, the 321 M Solvent Storage Tank, and A014 Outfall) would require more than 250 years using only SVE and groundwater pump and treat.

There are only a few general categories of technologies for addressing subsurface DNAPLnamely enhanced removal, in-situ destruction, and isolation. While some technologies/strategies may bridge these categories, most technologies can be classified by their principal mode of action. The discussion and associated table are organized into the three overarching classes. Within each class, a few example technologies are specifically identified and, where appropriate, as well as the most probable exemplar(s) for deployment. The exemplars will be selected based on availability, maturity, and the potential to leverage DOE investment. This approach simplifies the technical evaluation. It encourages consideration of a relatively large number of options and provides a structure to rapidly compare and contrast the options - especially in cases where the technologies in a class share many similar strengths and limitations.

The primary commercial, or near commercial, DNAPL source treatment options are described below and summarized on Table 1.

\section{Enhanced Removal:}

- Steam Flushing - This technology uses steam to sweep residual DNAPL from the subsurface and to deliver heat. This method is a cross over method originally developed and studied for enhanced oil removal (i.e., to increase the productivity of oil wells and oil fields. The primary mechanism of oil/DNAPL removal is concentration of the contaminant phase along the expanding steam front and collection at strategic locations. Typically, steam based remediation systems use a set of wells to deliver steam and move the contaminant phase towards "interior" collection wells to minimize the potential for spreading. In addition to the primary mode of action, steam provides heat energy to increase the mass transfer of contaminants from fine grained materials and increases DNAPL component vapor pressure and solubility. A final benefit of steam (and other in-situ heating methods) 
is that a fraction of the organic phase will break down in the subsurface in the presence of heat and oxygen. Steam is an extremely effective fluid for cleaning soil and groundwater. It delivers its energy efficiently in a minimal condensed volume (much of the energy is released as the steam front condenses). Steam is less dense than water. Thus, it will tend to be most effective and efficient in the vadose zone and in areas below the water table where the entire aquifer is contaminated rather than just a thin layer at the bottom of the treatment zone. Natural layering of sediments and careful design and operation will also limit the tendency of the steam to override the water table. There are a few commercial variants of steam heating. The most successful and widely used are by licensees of the Lawrence Livermore National Laboratory (LLNL) steam remediation processes. These particular processes are known as Dynamic Underground Stripping (DUS) and Hydrous Pyrolysis Oxidation (HPO) for the steam sweep and the abiotic oxidation phases, respectively. DUS and HPO were developed with the support of the DOE Office of Technology Development (OTD) and the Subsurface Contaminant Focus Area (SUBCON). Steam heating has been selected as the primary source treatment for the M Area Settling Basin and for subsequent cleanup of the A-014 Outfall. In virtually all variants of in-situ steam treatment, the steam is injected at high pressures and spreads rapidly through the formation. Heat is transferred to the formation and the steam front expands as the treatment zone reaches target temperatures near the boiling point of water. The rapid expansion of the steam zone reduces the required number of access points compared to many alternative technologies such as six phase heating or the reagent-based destruction/mobilization/solubilization methods. Recent developments in steam deployment, such as the injection of air at high pressure to modify the uniform symmetric shape of the pressure-dominated steam zone are promising for sites with limited access beneath a building or cap. This particular concept, originated and tested by Bo Stewart (Praxis) and modeled by Ron Falta (Clemson University) represents an additional new technology for deployment as part of an efficient in-situ steam treatment at the M Area Settling Basin.

- Six Phase Heating - This technology uses AC power to heat the soil through resistive ("Joule") heating. Through resistance to the flow of electricity in the bulk soil/groundwater, heat is generated. Thus, the ground itself acts in a manner analogous to the heating element in a small radiant home or office heater. This process normally requires some moisture to be maintained in the heated zone. Since the area immediately adjacent to the electrodes heats faster than the overall treatment zone, injection of small amounts of water or electrolyte solution is often required to allow the ground to be heated to temperatures near 100 degrees C. Dividing the power into six phases (rather than the traditional three phases) also helps avoid problems because the power density near each electrode is reduced and the overall power pattern is more uniform. An advantage of six-phase heating for vadose zone contamination is that power and heat are preferentially directed into fine grained or clayey layers. These layers tend to have a higher moisture content and have been shown to be the long term DNAPL reservoir in many layered geological systems such as A/M Area. Six phase heating was developed by Pacific Northwest National Laboratory (PNNL) and has been licensed for commercial implementation (Current Environmental Solutions). As with DUS, this process was originally funded and developed by the DOE OTD. The first field test of six phase heating was performed 
in the A/M Area of SRS. This test successfully heated a shallow contaminated clay underlying the former process sewer line leading to the M Area Settling Basin. Six phase heating is potentially applicable to similar DNAPL targets as steam but with less robustness to heat below the water table and the possible need for closer borehole spacing (to install electrodes). Six Phase heating is likely to be more robust than steam for low permeability conditions. Recent developments related to this technology include use of higher power density to generate an in-situ corona (to stimulate in-situ destruction in addition to mobilization). This particular enhancement has been observed in the laboratory and may not be suitable for initial field testing at a large contaminated site.

- Dual Media Extraction - This method, which is being performed by a large number of companies, is based on lowering the water table and removing the residual DNAPL using the relatively efficient soil vapor extraction (SVE). The water table lowering process can be accomplished on a local scale by using a high vacuum suction tube in the SVE well or, on a slightly larger scale, by using intensive pumping of a small number of closely spaced wells. Dual media extraction is promising for DNAPL sites that are smaller than the major sources in the A/M Area. Specific attributes that make dual media extraction promising include: residual DNAPL present in the capillary fringe and shallow groundwater, minimal DNAPL deep in aquifer zone(s) beneath water table, avoiding implementation at sites with either very high or very low permeability.

- Surfactant flushing - This technology uses surfactant solutions to solubilize or mobilize DNAPL. This enhancement allows DNAPL to be removed in a few pore volumes of flushing rather than the hundreds or thousands of pore volumes required if the DNAPL is dissolving into water. This technology has been studied for many years by various universities (SUNY Buffalo, University of Texas, University of Oklahoma, University of Florida, University of Waterloo, and others) and by Duke Engineering and Services Company. The process requires rigorous control on the injected and extracted fluids to assure that the DNAPL zone is swept by the injected reagent and to assure that the mobilized/solubilized DNAPL is effectively captured. A key element to the success is optimizing the use of the relatively expensive surfactants by developing recycle systems, more efficient surfactants, or other strategies. This technology has been applied with limited success at sites with favorable DNAPL source and geological conditions. Specific attributes that make this technology promising include: relatively small and well defined DNAPL target in permeable material below the water table, DNAPL present throughout formation and competent confining zones to help control undesirable migration away from treatment zone. Because it involves injection and extraction of reagent, this class of technology would have limited applicability above the water table and to clean up fine-grained layers. Recent research in this field is focused on surfactant recycle and reducing the buoyancy of mobilized DNAPL for more effective control and capture.

- Cosolvent Flushing: This technology is very similar to Surfactant Flushing in theory and approach, except that cosolvents (e.g., alcohols, and other such solvents) are used instead of aqueous surfactants. This type of remediation has been deployed by universities (e.g., Clemson University) with some success. In addition to research on redcucing the buoyancy of the mobilized DNAPL, cosolvent researchers are 
examining increasing the density of the reagent fluid to more effectively target "bottom-dwelling" DNAPL layers.

- Sparging: This technique, based on injection of air below the water table, has limited applicability to most DNAPL situations. A key exception is sites where small volumes of DNAPL are held up in the capillary fringe and sparge air can be directed up through the contaminated layer for collection by SVE.

\section{In-Situ Destruction:}

- In-Situ Oxidation: This technology uses reagents to destroy DNAPL in place. Typical reagents include Fenton's reagent (hydrogen peroxide and reduced iron) and permanganate solution. These reagents are strong oxidizers that "burn" the DNAPL in a saturated or vadose zone setting. As the reagent is added, it reacts vigorously and often induces bubbling and mixing - a process that may enhance contact of the reagent with the target DNAPL under some condistions. Several variants of in-situ oxidation methods have been deployed commercially. A key element to the success is performing the work rapidly with a minimal volume of reagent. Sites with highly reduced conditions (conditions that would scavenge reagent away from the desired DNAPL destruction) would be poorly suited to this technology class. Specific attributes that make this technology promising include: relatively small and well defined DNAPL target in permeable material, DNAPL present throughout formation, and competent confining zones to help control reagent delivery. Because it involves injection of reagent, this class of technology would have limited applicability to clean up fine-grained layers.

- In-Situ Bioremediation (Anaerobic or Aerobic): In-situ bioremediation is based on stimulating indigenous (or added) bacteria and other microorganisms to destroy or stabilize contamination. The most successful in-situ bioremediation processes are those applied to contaminants that are directly mineralized as part of the life cycle of the microorganisms (petroleum hydrocarbons and the like). Most DNAPLs are chlorinated or halogenated compounds that do not efficiently serve as primary carbon sources. Instead, breakdown of these compounds proceeds anaerobically by stepwise dehalogenation (and related mechanisms) or aerobically by cometabolism (as a result of crossover activity of enzymes induced by adding appropriate primary carbon sources). Neither of these bioremediation approaches is directly applicable to direct destruction of large volume DNAPL sources. Recent work by (e.g., Perry McCarty at Stanford University) suggests that anaerobic destruction methods at high aqueous concentrations ("near-DNAPL") may be relatively effective because the nutrients added to the system progress along metabolic pathways that maximize dehalogenation rather than alternative or side reactions. Anaerobic DNAPL remediation has been stimulated using a variety of amendments (lactic acid, molasses, vegetable oils, etc.). One commercial variant, Hydrogen Release Compound (HRC ${ }^{\mathrm{TM}}$, from Regenesis) is a solid amendment that has been successfully deployed at a number of sites using closely spaced boreholes. The current data suggest that bioremediation may not be viable as a primary source treatment method, but that it may be viable to treat areas immediately adjacent to the primary source. This is especially true for areas where the geometry of the target DNAPL is difficult to access. For example, some of the liquid reagents proposed for stimulating anaerobic 
degradation are denser than water so that they might effectively treat thin-low-volume DNAPL zones at the bottom of an aquifer zone.

\section{Source Zone Isolation Methods:}

These methods attempt to stabilize and address DNAPL by removing them from the active transport pathways soil and groundwater system. Because of the low concentrations needed to meet regulatory goals (e.g., $\mu \mathrm{g} / \mathrm{L}$ or ppb levels), isolation methods have not been successful to date. Thus, they are listed here for completeness and a commercial variant has not been identified. Even the carefully installed sealed sheet piles at Bordon site in Canada did not successfully eliminate the contamination of surrounding groundwater after DNAPL was added inside the test cell in a controlled experiment.

Table 1 summarizes the technologies described above. Also, this table qualitatively identifies the most promising DNAPL target(s) in terms of geometry and quantity and designates the appropriate zone identifiers from the conceptual model described above (e.g., Ia, IIb, etc.). It is clear that steam is an effective treatment method for the vadose zone as well as areas below the water table where a substantial portion of the aquifer is contaminated. In terms of the conceptual model, these are areas where there is vertical movement throughout the aquifer associated with the original source or a breach in a confining layer allowing transport from an overlying aquifer. These are the types of targets that will be pursued in the data analysis section below and in the ultimate implementation of steam/DUS for the M Area Settling Basin. 
Table 1: Summary of Commerical or Near Commercial DNAPL Source Remediation Methods.

\begin{tabular}{|c|c|c|c|c|c|}
\hline \multirow{6}{*}{ 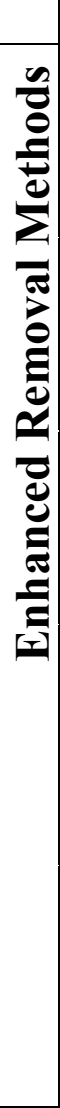 } & Technology & Summary Description & Requires & Preferred DNAPL Geometry $^{2}$ & Comments \\
\hline & Steam Flushing & $\begin{array}{l}\text { Uses high pressure steam } \\
\text { sweep to remove DNAPL }\end{array}$ & $\begin{array}{l}\text { Injection of steam (energy } \\
\text { and fluid) and extraction of } \\
\text { steam and contaminants }\end{array}$ & $\begin{array}{l}\text { I and II - medium to high } \\
\text { permeability (e.g., }>0.1 \text { darcy) } \\
\text { and/or layered sediments }\end{array}$ & $\begin{array}{l}\text { Poorly suited to zone III because of steam } \\
\text { density and cost. Also, use of air pressure } \\
\text { to modify treatment zone geometry may } \\
\text { be promising. }\end{array}$ \\
\hline & Six Phase Heating & $\begin{array}{l}\text { Uses electrodes and the } \\
\text { resistance of the earth to } \\
\text { generate resistive heat }\end{array}$ & $\begin{array}{l}\text { Injection of energy and } \\
\text { extraction of contaminants } \\
\text { and steam }\end{array}$ & $\begin{array}{l}\text { I and II }- \text { well suited vadose zones } \\
\text { clean up and low to medium } \\
\text { permeability e.g., }<0.1 \text { darcy) } \\
\text { below the water table }\end{array}$ & $\begin{array}{l}\text { Poorly suited to high permeability } \\
\text { sediments below water table and zone III } \\
\text { conditions. }\end{array}$ \\
\hline & $\begin{array}{l}\text { Dual Media } \\
\text { Extraction }\end{array}$ & $\begin{array}{l}\text { Uses wells for extraction of } \\
\text { water/DNAPL and } \\
\text { injection and extraction of } \\
\text { air }\end{array}$ & $\begin{array}{l}\text { Injection of air and } \\
\text { extraction of water, air and } \\
\text { contaminants. }\end{array}$ & $\begin{array}{l}\text { I and IIa - only for DNAPL in the } \\
\text { vadose zone, the capillary fringe } \\
\text { and upper portion of the water } \\
\text { table }\end{array}$ & $\begin{array}{l}\text { Poorly suited to low permeability or } \\
\text { highly layered sediments }\end{array}$ \\
\hline & \begin{tabular}{|l|} 
Surfactant Flushing \\
\end{tabular} & $\begin{array}{l}\text { Uses surfactant solution to } \\
\text { mobilize or solubilize } \\
\text { DNAPL for removal }\end{array}$ & $\begin{array}{l}\text { Injection of reagent and } \\
\text { extraction of water and } \\
\text { mobilized contaminants }\end{array}$ & $\begin{array}{l}\text { Small-defined DNAPL target in } \\
\text { any portion of the source } \\
\text { distribution. }\end{array}$ & $\begin{array}{l}\text { Poorly suited to large, dispersed or poorly } \\
\text { delineated DNAPL target. Poorly suited } \\
\text { to low permeability }(<0.1 \text { darcy) and } \\
\text { bottom dwelling DNAPL (unless reagent } \\
\text { is modified to be denser than water). }\end{array}$ \\
\hline & Cosolvent Flushing & $\begin{array}{l}\text { Uses cosolvent solution to } \\
\text { mobilize or solubilize } \\
\text { DNAPL for removal }\end{array}$ & $\begin{array}{l}\text { Injection of reagent and } \\
\text { extraction of water and } \\
\text { mobilized contaminants }\end{array}$ & $\begin{array}{l}\text { Small-defined DNAPL target in } \\
\text { any portion of the source } \\
\text { distribution. }\end{array}$ & $\begin{array}{l}\text { Poorly suited to large, dispersed or poorly } \\
\text { delineated DNAPL target. Poorly suited } \\
\text { to low permeability }(<0.1 \text { darcy) and } \\
\text { bottom dwelling DNAPL (unless reagent } \\
\text { is modified to be denser than water). }\end{array}$ \\
\hline \multirow{2}{*}{ 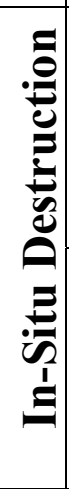 } & $\begin{array}{l}\text { In-Situ Chemical } \\
\text { Oxidation }\end{array}$ & $\begin{array}{l}\text { Uses strong oxidizer (e.g., } \\
\text { peroxide or permanganate) } \\
\text { to mineralize solvent in } \\
\text { soil and groundwater } \\
\text { systems }\end{array}$ & Injection of reagent & $\begin{array}{l}\text { Small-defined DNAPL target in } \\
\text { any portion of the source } \\
\text { distribution. Vigorous reaction } \\
\text { provides some mixing in the } \\
\text { groundwater system. }\end{array}$ & $\begin{array}{l}\text { Poorly suited to large or poorly delineated } \\
\text { DNAPL target. Poorly suited to low } \\
\text { permeability }(<0.1 \text { darcy) and bottom } \\
\text { dwelling DNAPL (unless reagent is } \\
\text { modified to be denser than water). }\end{array}$ \\
\hline & $\begin{array}{l}\text { In-Situ } \\
\text { Bioremediation }\end{array}$ & $\begin{array}{l}\text { Uses nutrients and other } \\
\text { amendments to stimulate } \\
\text { biological mineralization in } \\
\text { soil and groundwater } \\
\text { systems }\end{array}$ & Injection of reagent & $\begin{array}{l}\text { High concentrations near DNAPL } \\
\text { or areas containing small amounts } \\
\text { of DNAPL. }\end{array}$ & $\begin{array}{l}\text { Poorly suited to large DNAPL } \\
\text { accumulations. Poorly suited to low } \\
\text { permeability }(<0.1 \text { darcy) and bottom } \\
\text { dwelling DNAPL (unless reagent is } \\
\text { modified to be denser than water). }\end{array}$ \\
\hline
\end{tabular}

Notes:

1. Includes only commercial or non-commercial technologies. Excludes some experimental methods and methods that have not been successfully commercialized (e.g., radio frequency heating, or in-situ chemical reduction).

2. DNAPL geometry codes are based on conceptual model developed and presented above. 
WSRC-TR-2001-00198

Proposed Steam Treatment and Objectives (summarized from DOE Groundwater Initiatives Proposal)

The Savannah River Site (SRS) proposes deployment of Dynamic Underground Stripping (DUS) in order to remediate source term DNAPLs at the M Area Settling Basin. The program strategy is to aggressively remove source term material while addressing the dissolved portion of the plume through a passive, lower cost approach, where applicable. In particular, we propose accelerating the ongoing remediation of soil and groundwater using steam flushing. Steam flushing is a commercially available process that accelerates DNAPL removal by heating the contaminated soil region - vaporizing contaminants for collection. The process has been deployed at several sites in the United States, including the 321-M Solvent Storage Tank Area at SRS. Control of the process is achieved by temperature monitoring and underground imaging using electrical resistance tomography (ERT). These techniques delineate the heated area and track the steam fronts. In general, the proposed location of the deployment is at the M-Area Settling Basin located to the south and west of the former M Area Settling Basin. During operation of M Area, approximately 2 million pounds of solvents were released to this facility via a process sewer line. This area is considered a primary target for source removal to address long term contamination in the Western and Southern Sectors of A/M Area (Jackson, Payne et al. 1996).

The steam flushing process is technically complex and requires a detailed planning and design effort. In the initial stages of project planning an approximate target volume of 190,000 cubic yards ( 1 acre plot $\mathrm{x} 120$ feet deep) served as the basis for budgeting. The baseline for soil cleanup of DNAPL solvents in A/M Area (ERD Baseline 98 Plan) is operation of 6 SVE units until FY2023 for vadose zone contamination removal. The baseline process for groundwater remediation is pump and treat using the A2 and M1 Air Strippers until FY 2023. It is important to note that actual operations are anticipated to extend well beyond 2023 for these systems if no additional source term remediation is implemented. By removing the free phase DNAPL, SRS proposes that operation of two or three of the recovery wells feeding the M1 Air Stripper could be eliminated; hence, reduction of long term stewardship costs. In addition, one SVE unit (two horizontal wells) would be retired following steam flushing. The elimination of the source term would also be reflected in eliminating Western Sector recirculation wells and retiring the Southern Sector recirculation wells (remediating the dissolved Southern Sector plume). In the section below, these preliminary estimates are refined by detailed examination of DNAPL characterization data collected over the past 18 years. 
WSRC-TR-2001-00198

\section{Relevant A/M-Area DNAPL Characterization Data:}

In the section below, the historical DNAPL characterization data are summarized and presented in a form to support delineation of the various DNAPL source and migration patterns described in the conceptual model previously illustrated in Figure 5 and Figure 6. Historical A/M-Area data related to subsurface DNAPL has been reported and interpreted in several technical reports and in the RCRA permit and related documents. A brief history of A/M Area DNAPL characterization activities is provided in Appendix A. An example of the results of the various studies is shown in Figure 7. This was an early summary map that showed which groundwater monitoring wells were in an area of "suspect DNAPL" migration. These wells yielded water at a conservative screening concentration of $1 \%$ of solubility (Jackson, Payne et al. 1996). The pattern of suspect DNAPL wells helped delineate the general pattern of DNAPL contamination in A/M Area and clearly identified the most significant DNAPL source areas - the M Area Settling Basin, the A-014 Outfall, and the 321 M Solvent Storage Tank. In 2001, all of the available historical concentration data - groundwater, soil gas and soil plug -- were compared to various DNAPL screening levels and examined considering the spatial relationship to known and potential source areas and the controlling subsurface geologic complexity of the A/M Area (Vangelas 2000). This summary map, presented in Figure 8, is a significant update of the simple groundwater concentration screening and posting performed earlier. As described below, the assessment of A/M DNAPL has been refined over time. Current interpretation extends beyond the two-dimensional posting maps, providing more details on the specific distribution of DNAPL in the soil and groundwater near identified sources.

Extending the posting of DNAPL screening results into three dimensions is a useful method to visualize the various DNAPL migration and accumulation zones near key A/M Area sources. To facilitate such a three-dimensional visualization in the vicinity of the M-Area Settling Basin and the influent process sewer line, we have created a series of figures (Figure 9 through Figure 15) comprised of various standard elements. In the upper left is a plan view map of the block of earth being visualized. The rectangles below and to the right of the plan view map are views through the block looking from the south and the east, respectively. In other words, the south and east views are folded up and placed next to the top (map) face of the block. The figure is completed with a legend showing the various symbol shapes and colors used in the posting.

All of the relevant historical data collected in the visualization block have been compared to various DNAPL screening criteria. Data for all sampling media - aqueous liquid, soil solid and gas phase - are included in the posting. For each medium, four DNAPL screening categories are defined by three numerical screening values. For aqueous liquid samples, numerical screening criteria of $1 \%, 10 \%$ and $100 \%$ of solubility are used to define whether a sample is collected from an area where: DNAPL is unlikely, DNAPL is possible, DNAPL is probable, or DNAPL is observed. The numerical screening criteria in this case are the "rules of thumb" commonly used in DNAPL assessment and documented in the literature (Cohen and Mercer 1993; Pankow and Cherry 1996). The screening criteria for bulk core concentration (solids) and for gas samples are similar in derivation to the liquid screening values (Pankow and Cherry 1996; Eddy-Dilek et al. 1998; Vangelas 2000). The specific numerical screening values used to make the posting are provided in Table 2 . 
Table 2: DNAPL Screening Categories and Numerical Screening Criteria applied.

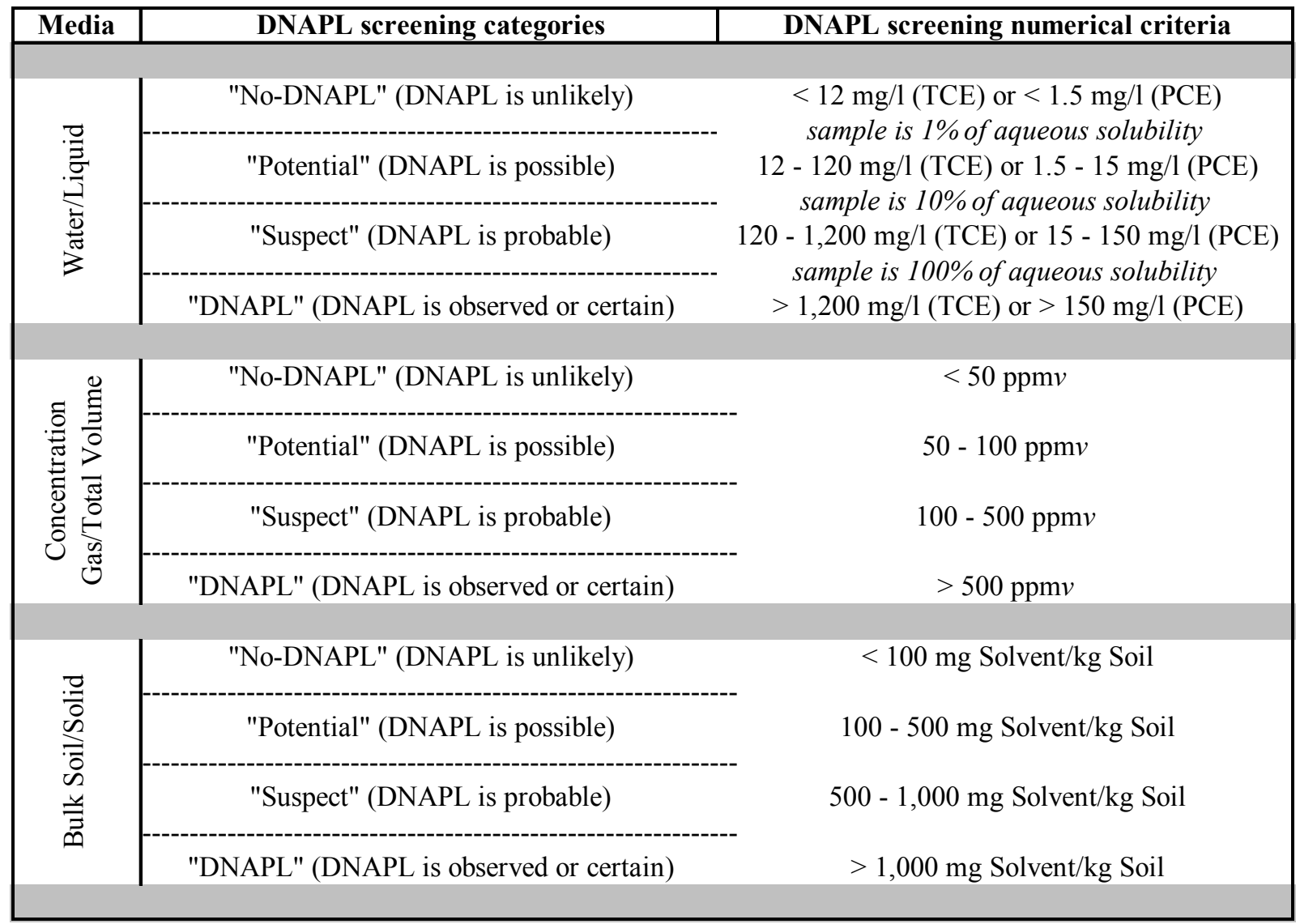

The data for the different sample media are posted with different symbols while the colors used for the four DNAPL screening levels is consistent across the various media (green indicates DNAPL is unlikely ranging to red indicates that DNAPL is certain). It is important to note that the postings represent all of the relevant data in the block - the viewer is looking all the way through the domain so that higher or lower screening levels may appear together when they are in fact in front of or behind each other. When developing the conclusions for the report, the technical team viewed the images from many angles to assist in the final interpretation presented.

A representation of the sediment texture/lithology was the final item added to the figure to assist in interpretation. The various layers that might influence DNAPL migration and control accumulation above and below the water table were added as a colored background to the figure. The layer identifiers and the colors used are shown in the legend. The lithologic adaptation was based on recent investigations that focused on the variability of facies within the subsurface (Smits et al. 1998; Parker et al. 1999). In this investigation the role of the subtle variations in facies identified in the cited investigations is significant and considered to have a significant effect on DNAPL migration and distribution. These subtle variations are associated with the migration from Zone IIIa to Zone IIb conceptually illustrated in Figure 6. For simplicity and clarity in presentation the lithology depicted is representative of a cross section of lithology underlying the basin (from west to east) and underlying the former process sewer line (from north to south). 
Combination of the lithology information with the three-dimensional DNAPL screening criteria posting provides a relatively clear visualization of the controlling processes and the location of DNAPL migration and accumulation in the vicinity of the M-Area Settling Basin. Conceptually, once spent solvent were released from the process facilities in A/M Area to the process sewer system, solvents entered the subsurface either from leaks along the sewer or directly once at the M-Area Settling basin. Once in the subsurface the DNAPL migrated vertically across the vadose zone until reaching the capillary fringe at a historical elevation between 240 and 245 feet above mean sea level. The extensive characterization data in Figure 12 is associated with the vadose zone and illustrates this vertical migration pattern. As illustrated in this figure, a significant amount of the data in direct proximity to the abandoned process sewer and the M-Area Settling Basin has been categorized as either "Suspect" or "DNAPL" based upon the criteria presented in Table 2. This region is considered representative to Zone I illustrated in Figure 6, and as discussed in previous discussions is directly amenable to remediation using stream flushing techniques. An important consideration in the identification of the heating zone is that angle drilling around the M-Area Settling Basin indicates that most of the residual DNAPL in the vadose zone is confined to a much smaller horizontal footprint than that of the historical basin. This extent is smaller, possibly as small as $25 \%$, than that which would be anticipated from a cursory examination of the basin as a DNAPL source zone. The basis of the reduced footprint is considered to be associated with the topographic relief of the bottom of M-Area Settling Basin. As presented in historical documents associated with the facility (Colven, Pickett et al. 1984; Marine and Bledose 1984), the basin was deepest in the North/Northeastern corner due to a topographic depression associated with the bottom of the basin. This depression would have served to accumulate DNAPL and most likely served as the primary entry zone for DNAPL into the subsurface.

Upon reaching the elevation of the historical capillary fringe, vertical DNAPL migration was impeded. Whether the DNAPL penetrated the water table and continued to migrate vertically was dependent upon the driving force associated with DNAPL migration (Cohen and Mercer 1993; Pankow and Cherry 1996). For the geologic conditions within A/M Area, previous investigators estimated that $1.1 \mathrm{~m}(3.7 \mathrm{ft})$ of accumulation was necessary to penetrate the capillary fringe (Jackson, Payne et al. 1996). Based upon the magnitude and period of releases to the M-Area Settling Basin, it is very likely that DNAPL would have penetrated the capillary fringe and migrated below the water table. This migration is represented conceptually as Zone IIa in Figure 6. Once within the saturated portion of the subsurface, continued migration of the non-aqueous phase would be a combination of vertical and horizontal, dependant upon parameters such as local permeability, DNAPL driving force, and the continuity and extent of finer-grained units.

Previous investigators have identified three (3) separate fine-grained layers that appear to have a significant impact on controlling the migration and extent of DNAPL in the vicinity of the MArea Settling Basin (Jackson, Payne et al. 1996). The first is the informally named " 230 -foot Clay" in which monitoring wells MSB-3D and MSB-22 are screened on top of. As indicated by the accumulation of DNAPL in these wells (Looney, Rossabi et al. 1992), this fine-grained layer is considered to be associated with migration towards MSB-9 and further west (Jackson, Payne et al. 1996). This migration is analogous to zone IIIa illustrated in Figure 6. As a sufficient driving force is present through continued release at the M-Area Settling Basin, the edge of the DNAPL would have continued to move westward until the driving force was removed or local variations in geology (i.e. an increase in permeability) allowed vertical migration. Based on the 
characterization data presented in Figure 13. lateral migration along the " 230 -foot" interval most likely occurred from the M-Area Settling Basin westward to the extent of MSB-10. The presence of this migration route is supported by extensive characterization data associated with Fenton's chemistry demonstration performed in 1997 (Jerome, Riha et al. 1997) between MSB-9 and MSB-10. In the vicinity slightly west of MSB-10, local variations in geology most likely allowed vertical migration driven by gravitational forces associated with the density difference between DNAPL and water. West of the basin, the "Green Clay" confining zone impeded further vertical migration and continued lateral migration would have occurred. Lateral migration along the "Green Clay" confining zone is controlled by the structure and texture of the unit and is considered to be the source of historically elevated concentrations observed at monitoring wells MSB-12, MSB-17, and MSB-76 (Jackson, Payne et al. 1996). This migration route is indicated in Figure 13, which suggests DNAPL moving laterally along an elevation of 230 feet and then resuming westward at an elevation of 200 feet. The westward migration along the "Green-Clay" is analogous to the IIIb zone illustrated in Figure 6

The third locally extensive fine-grained layer controlling migration in A/M Area is the variable clay that informally separates the Lost Lake into upper and lower portions (Jackson, Payne et al. 1996). This clay layer has been historically referred to in stratigraphic investigations as the "Four-Mile Member of the Fishburne Formation." In previous investigations this unit was discussed relative to historical operations at the 321-M Solvent Storage facility (Jackson, Payne et al. 1996). In this investigation, the unit is considered as a maximum depth boundary for DNAPL that is targeted for steam based remediation. The available characterization data associated with the lower portion of the Lost Lake aquifer and the upper clay of the Crouch Branch confining unit is inconclusive with regards to the maximum depth in which DNAPL has penetrated. Although characterization data associated with the Crouch Branch confining unit (Figure 15 classify regions near the basin as either "Suspect" or "Potential," this classification is based on high aqueous concentrations from monitoring and multi-level recovery wells. These high aqueous concentrations are considered to be associated with aqueous transport from upgradient DNAPL present on the Green Clay (Jackson, Payne et al. 1996).

Another important aspect of selecting this clay as the maximum depth is associated with the buoyant nature of steam. As discussed in previous sections on enhanced removal techniques, steam is considered efficient and effective in the vadose zone and in areas below the water table where the entire aquifer is contaminated rather than just a thin layer at the bottom of a treatment zone. Due to the buoyant nature of steam, to effectively address thin layers of DNAPL in the saturated zone, steam should be deployed from below, so that the buoyant forces associated the steam direct DNAPL migration front towards the collection point(s). If DNAPL is present in the lower portion of the Lost Lake aquifer, the amount present is considered significantly lower than that on the Green Clay and on the "Four-Mile Member of the Fishburne Formation," and strategic deployments of one of the alternative technologies previously presented should be considered. 


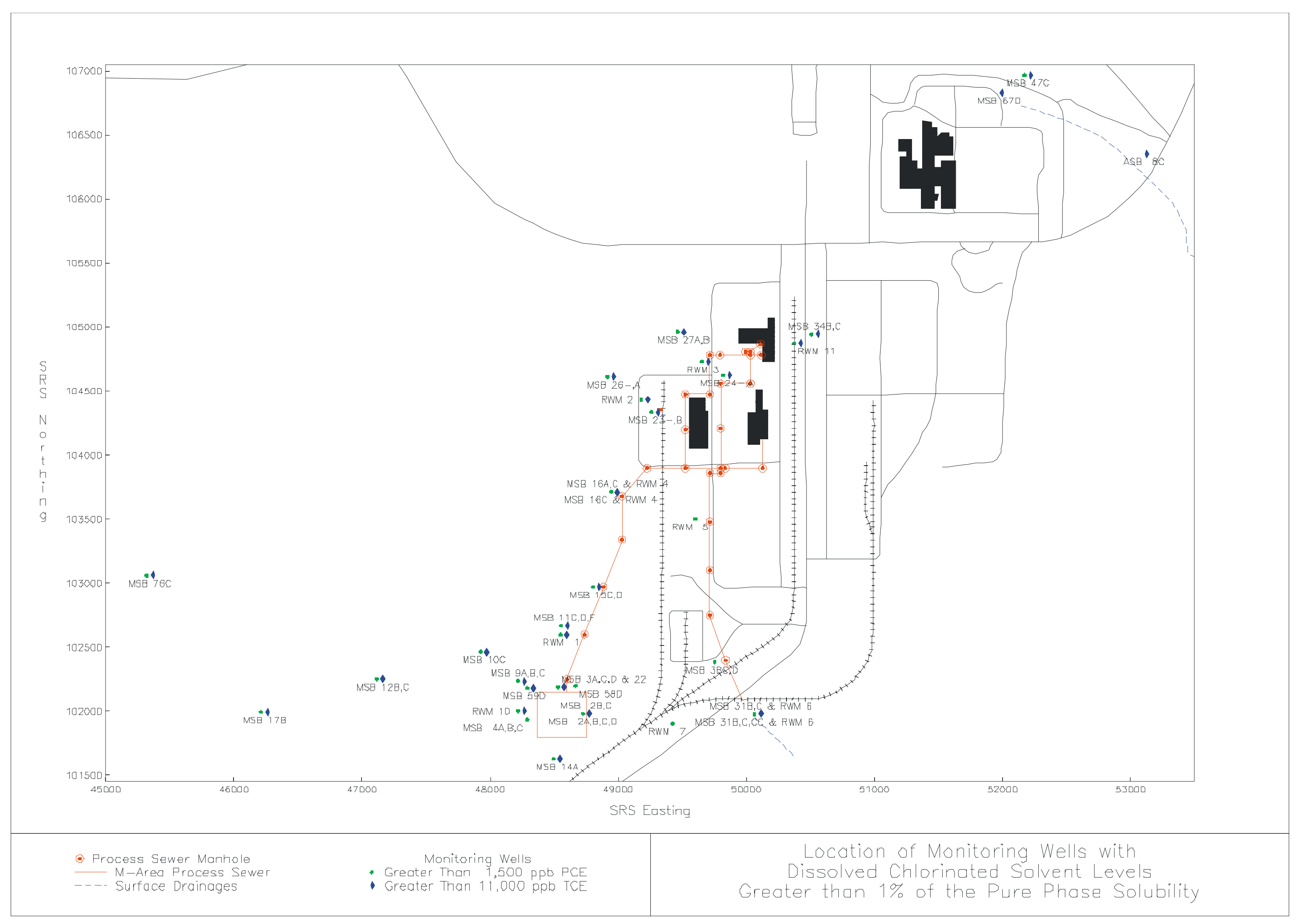

Figure 7: Historical Plan View Two-Dimensional Posting Map Showing the Location of Groundwater Monitoring Wells Exceeding 1\% of DNAPL Solubility (Jackson, Payne et al. 1996). 









Figure 9: Three-Dimensional Distribition of DNAPL Characterization Data Associated with Western Sector. (Note that the M-Area Aquifer and Green Clay Units are shown Semi-Transparent.) 


\section{('भf) 8u!yp.10 N SHS}


Figure 10: Extent of Western Sector Source and Migration showing major lithographic units considered significant in controling DNAPL migration. 
(') 8น!นา.10 N SHS
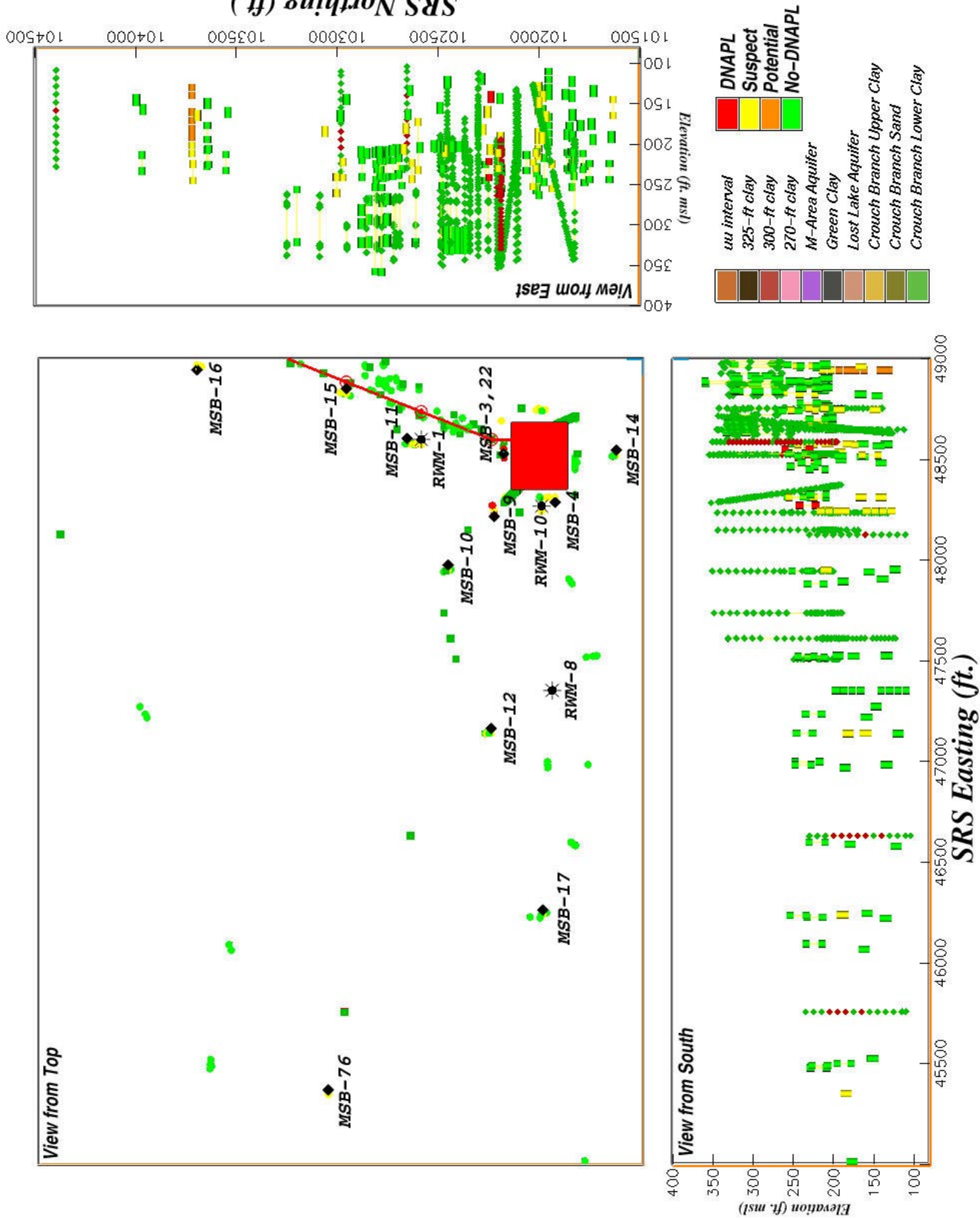

Figure 11: Location and Distribution of DNAPL Related Characterization Data in Associated with Western Sector Source and Migration. 


\section{('भf) $84 ! 41.10 \mathrm{~N}$ SHS}


Figure 12: Location and Distribiution of DNAPL Related Characterization Data Associated with Residual DNAPL in the Vadose Zone. 


\section{('भf) 8u!yp.10 N SHS}
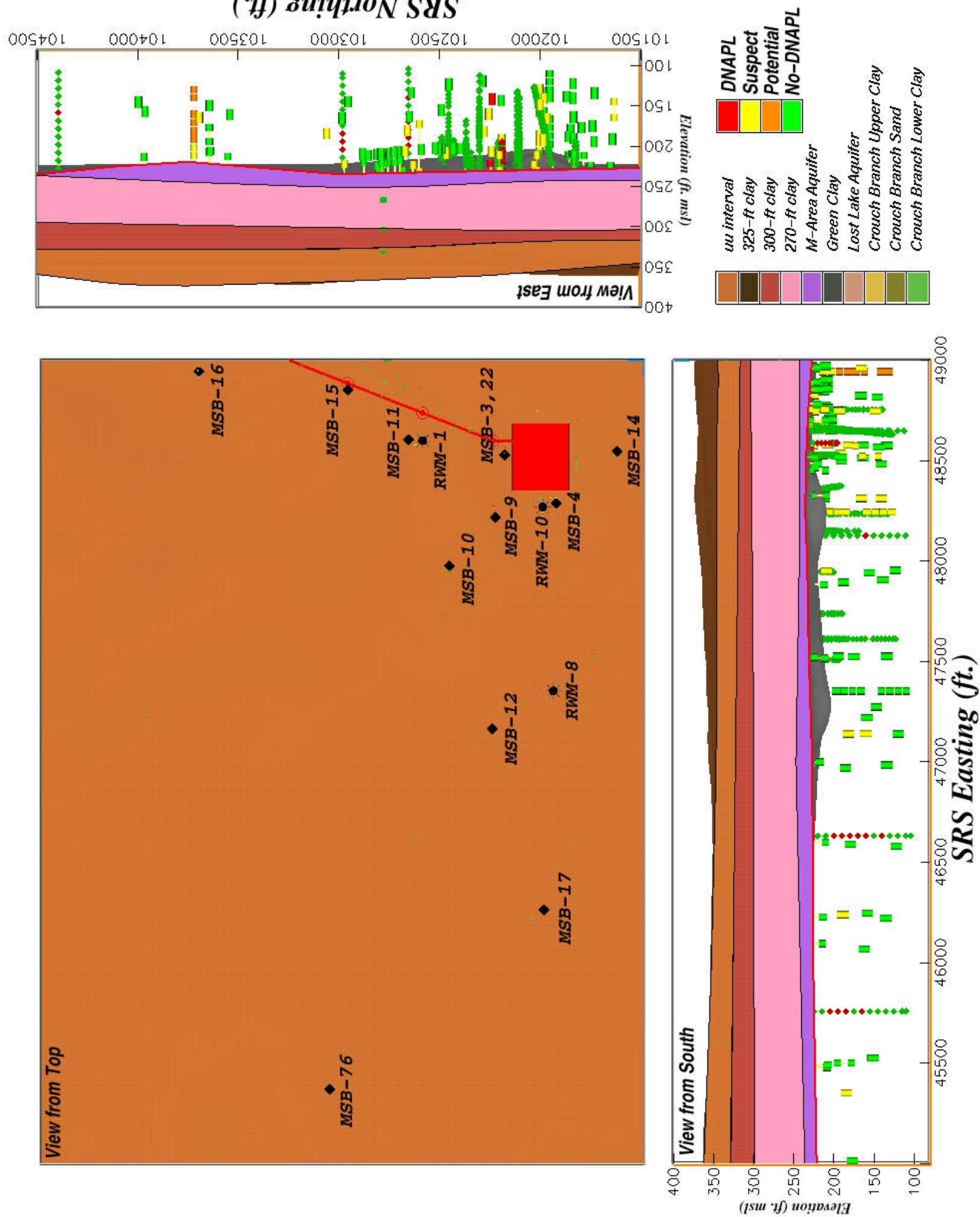

Figure 13: Location and Distribiution of DNAPL Related Characterization Data Associated with DNAPL beneath the Water-Table. 


\section{('भf) 8u!yp.10 N SHS}
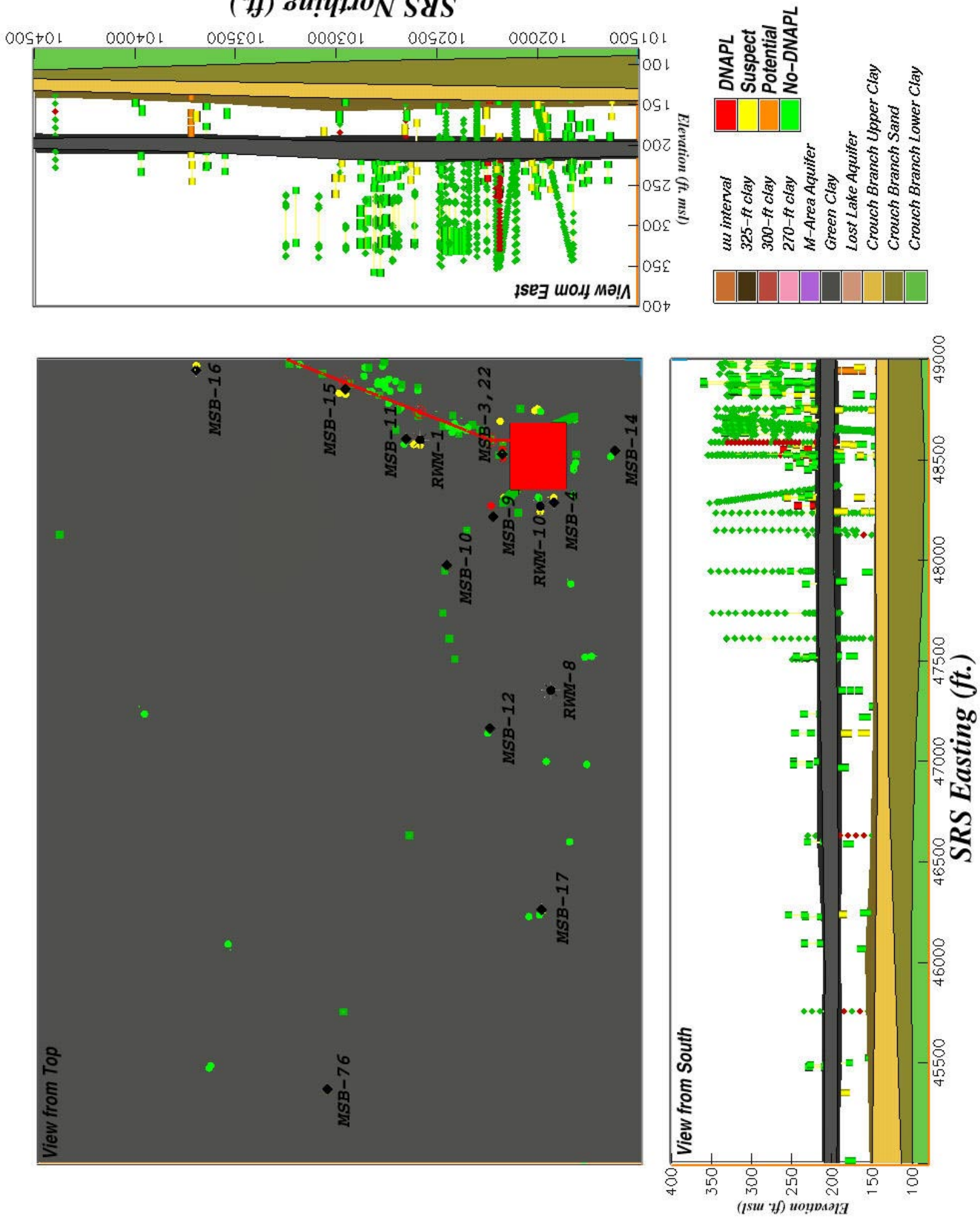

Figure 14: DNAPL Related Characterization Data in the Vadose Zone, M-Area Aquifer, and Lost-Lake Aquifer. 


\section{('भf) $81141.10 \mathrm{~N} \mathrm{SHS}$}
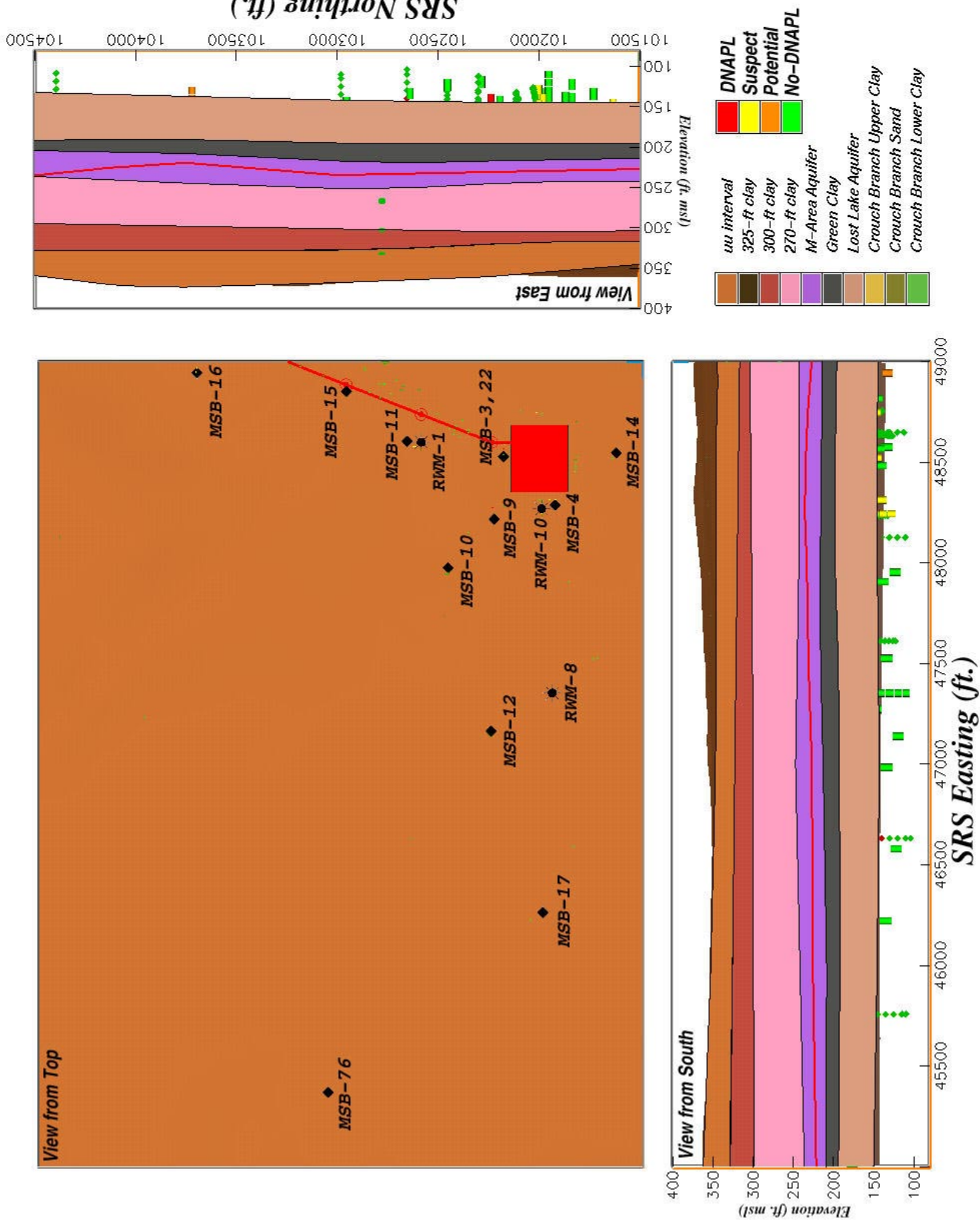

Figure 15: Location and Distribiution of DNAPL Related Characterization Data Associated with the Three (3) Layers of the Crouch Branch Confining Unit. 
WSRC-TR-2001-00198

\section{Identification of DNAPL Target Treatment Zones:}

Based on the examination and presentation of historical characterization data associated with the subsurface in the vicinity of the M-Area Settling Basin, numerous source remediation scenarios were developed and examined that focus on combinations of the various zones conceptualized in Figure 6 and discussed in the previous section. These scenarios include a minimum volume scenario, a maximum volume scenario, and a strategic volume scenario. Since aggressive DNAPL remediation strategies are based directly on the volume of the subsurface treated, effective deployment is dependent on directing treatment amendments in an efficient and effective manner. As such, each of the scenarios presented varies significantly in both the horizontal and vertical directions. In developing these scenarios the specific treatment zones presented in Figure 6 are discussed and incorporated into the different scenarios proposed. The horizontal extent associated with each of these treatment zones is presented in Figure 16. The minimum volume scenario encompasses only the portion of the subsurface with confirmed (observed or certain) DNAPL. The maximum volume scenario encompasses most of the subsurface region with possible DNAPL. The strategic case balances these end casesincorporating most of the subsurface volumes with suspect DNAPL and key areas that are designated as possible DNAPL migration or accumulation zones. As discussed below, other important balancing criteria incorporated into the strategic case include: a) the effectiveness/efficiency of the subject steam remediation approach to address the observed DNAPL geometry in each portion of the subsurface, and b) related observations such as time histories from monitoring wells or remediation well concentrations.

\section{Treatment Zones:}

Treatment Zone I: Having received an estimated 2 million pounds of chlorinated solvent from the M-Area processes (Marine and Bledose 1984), the immediate vicinity around the M-Area Settling basin is recognized as a primary DNAPL source area and should be considered in any aggressive DNAPL specific remediation. Historical groundwater concentrations indicate that residual NAPL is present in the shallow groundwater around this facility (Jackson, Payne et al. 1996). Ongoing remediation near the facility includes aggressive pump \& treat for groundwater using recovery wells RWM-1, RWM-8, and RWM-10 and soil vapor extraction in the vadose zone using horizontal wells immediately beneath the basin. Previous investigations have examined the capture zone associated with the groundwater recovery wells (Jackson and Aleman 1995) and the effectiveness of soil vapor extraction system (Jarosch, Jackson et al. 1997). More recent investigations (Riha et al. 2001) associated with vadose zone operations along the abandoned process sewer, propose a series of wells to provide a pressure boundary to facilitate barometric pumping. This proposed pressure boundary was used to define the northern extent of Zone I. Because Treatment Zone I is associated with the vadose zone, the zone extends to the depth of the water table.

Treatment Zone IIa and IIIa: These zones include that portion of the M-Area aquifer zone immediately beneath the basin and the vadose zone source (Zone I) and also includes those regions where significant DNAPL has accumulated and migrated along the 230-foot and GreenClay intervals. Historical groundwater concentrations for trichloroethylene and tetrachloroethylene from the groundwater recovery wells are presented in Figure 17 and Figure 18, respectively and are used to define the horizontal extent of Treatment Zone IIa and IIIa. As 
indicated in these figures, groundwater concentrations at all three wells are currently above regulatory criteria and are at concentrations which would suggest nearby DNAPL (Jackson, Payne et al. 1996). Historically recovery well RWM-1 has had the highest concentration, followed by recovery well RWM-10, and then recovery well RWM-8. Since pump \& treat operations began in 1985, the historical concentrations at recovery well RWM-1 have generally declined by almost an order of magnitude for trichloroethylene, while those from recovery well RWM-10 have remained relatively constant. An interesting observation associated with the historical concentrations from recovery well RWM-8 is the order of magnitude increase that occurred in both trichloroethylene and tetrachloroethylene concentrations. This increase in concentration occurred between January of 1989 and January of 1993 and suggests that the DNAPL is present in the subsurface near this well.

Treatment Zone IIb and IIIb: DNAPL that was continually released at the M-Area Settling Basin promoted westward migration towards MSB-12, MSB-17, and possibly as far west as MSB-76. The migration path is complex and governed by the distribution of finer grained sediments. Migration along this route is primarily density driven with gravitational forces controlling migration in the direction associated with local variations in slope. Previous investigations developed and applied a heuristic density driven model to evaluate the effect of the structure contour of the "Green Clay" confining zone on DNAPL migration (Jackson, Payne et al. 1996). Using various geologic interpretations for the structure of the "Green Clay" confining zone, these investigators concluded that westward migration along geologic strata was possible. It was further noted that subtle variations in elevation and/or geologic texture would significantly effect the results. The delineation of the horizontal extent of Treatment Zone IIIb incorporates the results from this investigation that proposed that DNAPL had migrated as far west as MSB-76C.

A summary of the volumes associated with the various treatment zones described is presented in Table 3. Since each of the treatment zones are associated with discrete regions of the subsurface, this table delineates the volume of each treatment zone with respect to the various units associated with the vadose and saturated zones. Within this and the subsequent tables, the volume estimates presented for the Lost Lake aquifer zone are considered to be maximum estimates. The estimates presented for the Lost Lake aquifer zone represent the volume associated with the entire vertical extent for each of the Treatment Zones described. For the deployment of DNAPL remediation system, only the upper portion of this aquifer zone would be addressed. This portion is generally delineated by the "Four-Mile Member of the Fishburne Formation" discussed in previous sections. Further delineation of this formation would require additional interpretation of available characterization data.

\section{Remediation Scenarios:}

The maximum volume scenario includes all of the Treatment Zones identified. This scenario was selected based primarily from a review of historical DNAPL indicators and likely mechanisms of westward DNAPL migration along the "Green-Clay" confining zone. The extent of this region extends westward from the M-Area Settling Basin to the vicinity of monitoring well cluster MSB-76C. The width of this deployment scenario is based on historical concentrations and potential DNAPL migration paths presented by previous investigators (Jackson, Payne et al. 1996). This scenario provides an aggressive remediation strategy encompassing all of the target remediation zones illustrated conceptually in Figure 6 . The maximum volume scenario includes 
the primary source areas around the M-Area Settling Basin. The treatment volume associated with this scenario is 6,143,474.59 cubic yards and is summarized in Table 4

In determining the minimum volume associated with DNAPL specific remediation near the MArea settling basin, the remediation of the vadose zone and shallow groundwater within the vicinity of this source is considered a principle objective. As presented in the previous section, the vadose zone beneath the M-Area Settling basin is considered to have residual solvents present mostly in the finer-grained materials. The characterization data has effectively reduced the size of the source area to that representing a horizontal area less than $50 \%$ of that of the actual settling basin. The vertical extent is limited to the deep vadose zone, as characterization data indicate that the active soil vapor extraction system using horizontal wells has effectively removed residual DNAPL in this portion of the vadose zone. The treatment volume associated with the minimum scenario is $156,922.39$ cubic yards and is summarized in Table 5.

The strategic volume scenario attempts to establish a reasonable balance between the limited volume of primary source near the M-Area Settling and the extensive volume associated with the maximum volume scenario. In establishing this balance, numerous parameters were considered and evaluated. These included trends and directions of historical groundwater concentrations, effectiveness and observations from active groundwater treatment systems, technical limitations of steam flushing relative to DNAPL geometry, and the economic issues and challenges associated with deployment over such an expansive horizontal extent.

The lateral extent of the maximum treatment scenario is driven primarily by the hypothesis that DNAPL has migrated westward along the "Green-Clay" confining zone towards monitoring well MSB-76C, a distance of over 3000 feet. This hypothesis is based on elevated groundwater concentrations for trichloroethylene reported at wells MSB-10C, 12B, 12C, 17B, and 76C and elevated concentrations for tetrachloroethylene at MSB-10C, 12B, 12C, and 17B along this path (Jackson, Payne et al. 1996). Since this evaluation was performed in 1996, an additional 5 years of groundwater monitoring data has been collected from monitoring wells MSB-12B, 17B, and 76C. This data has been combined with the previous data and is presented in Figure 19 and Figure 20 for trichloroethylene and tetrachloroethylene, respectively. As indicated by this information, since 1994 the historical trichloroethylene concentrations at monitoring well MSB$76 \mathrm{C}$ have steadily declined, while concentrations at monitoring wells MSB-12B and MSB-17B have remained relatively constant for trichloroethylene, and for MSB-12B, have increased for tetrachloroethylene. Monitoring was not performed at MSB-10C and MSB-12B during the past 5 years. Reinstatement and continued monitoring at MSB-10C, 12B, 12C, 17B, and 76C will be necessary to assess the effectiveness of any proposed remediation along this potential DNAPL migration route.

The strategic scenario extends westward towards recovery well RWM-8. The horizontal extent of the strategic scenario is coupled strongly with historical pump \& treat operations associated with this recovery well. As presented in Figure 17and Figure 18 historical concentrations at RWM-8 increased by an order of magnitude between 1989 and 1993. This increase is considered to be associated with groundwater from DNAPL source areas being captured by this system. Assuming that groundwater from subsurface DNAPL is directed towards RWM-8 due to pumping operations, a simple analytical solution can be used to evaluate operation and performance of this well. The analytical solution selected is the Ogata-Banks solution for 1dimensional transport in a column (Fetter 1994; Domenico and Schwartz 1998). These results are presented in Figure 21 and support the assumption that subsurface DNAPL within the capture 
zone has influenced concentrations at RWM-8. Since the increase occurred approximately 5 years after pump \& treat operations began, the 5-year capture zone (Jackson and Aleman 1995) associated with this well is used as a reasonable bound for where DNAPL exists. This is the basis in determining the horizontal extent for the strategic volume scenario. This scenario has a total volume of 294,090.46 cubic yards and is summarized in Table 6. By extending this scenario to the 5-year capture zone, one can conclude that an additional 5-years of post-remediation pump \& treat operation will be required at RWM-8. 


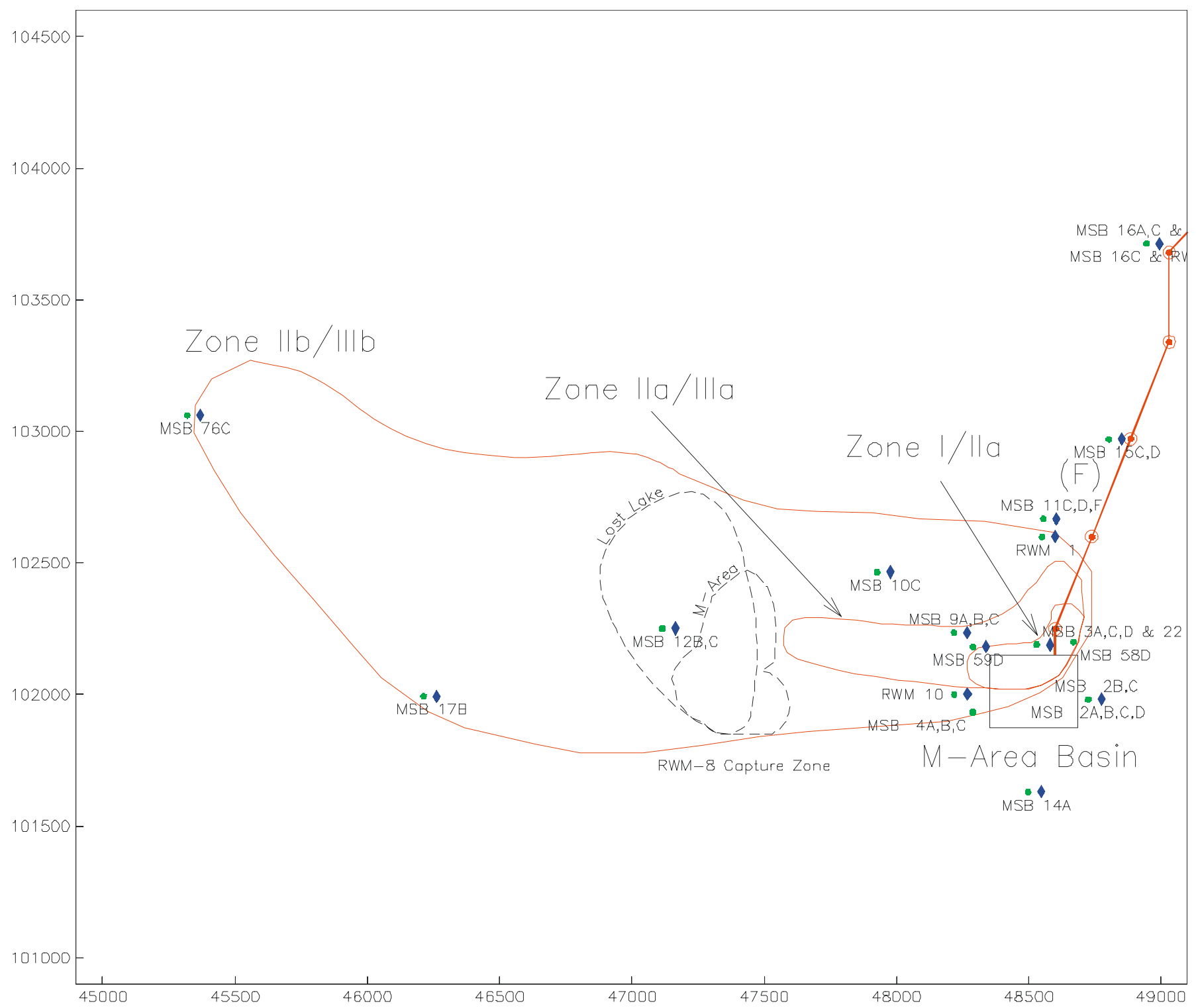

Figure 16: Horizontal Extent of Proposed Treatment Zones for DNAPL specific Remediaiton associated withWestern Sector. 


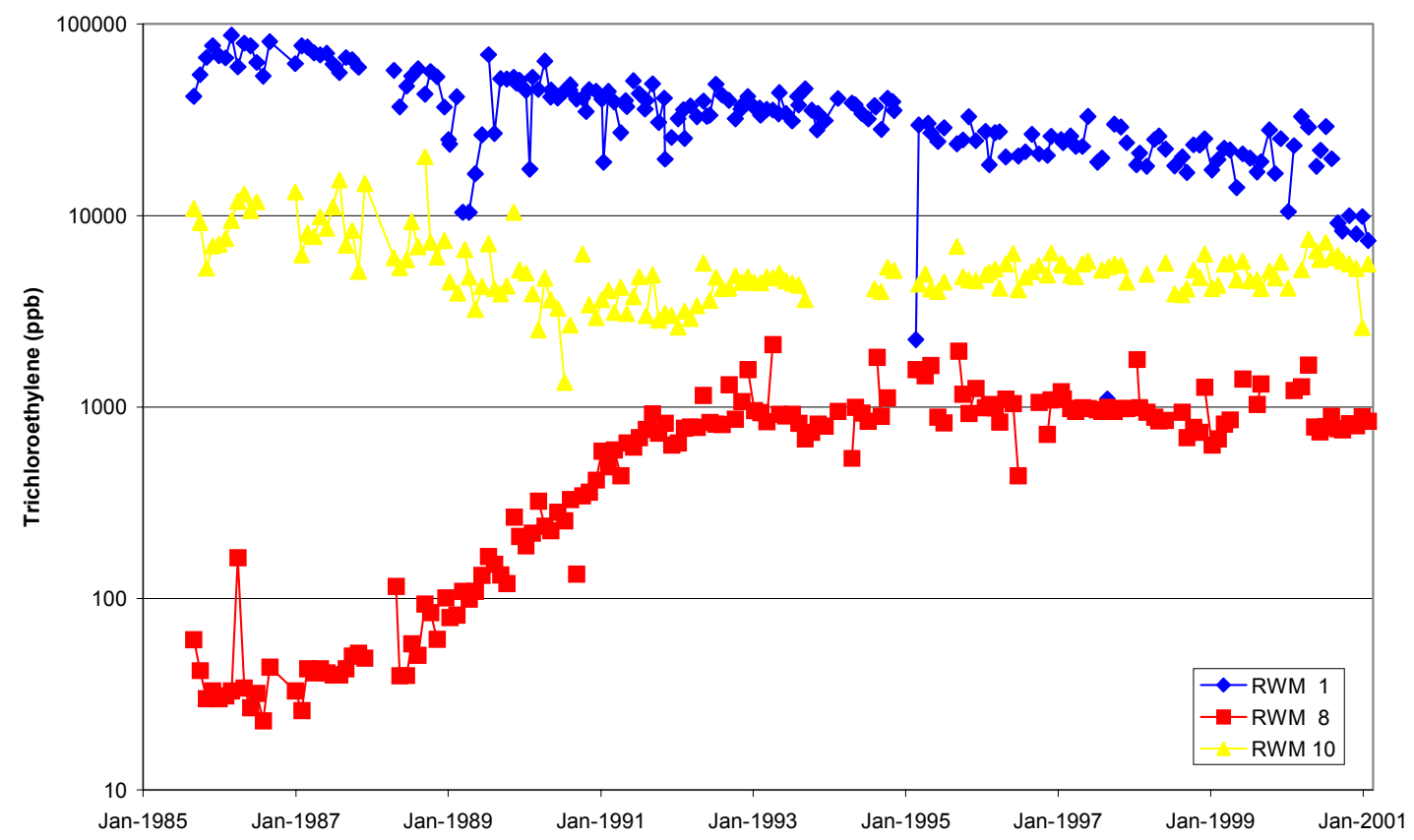

Figure 17: Trichloroethylene Concentrations from RWM 1, RWM 8, and RWM 10.

Tetrachloroethylene Concentrations

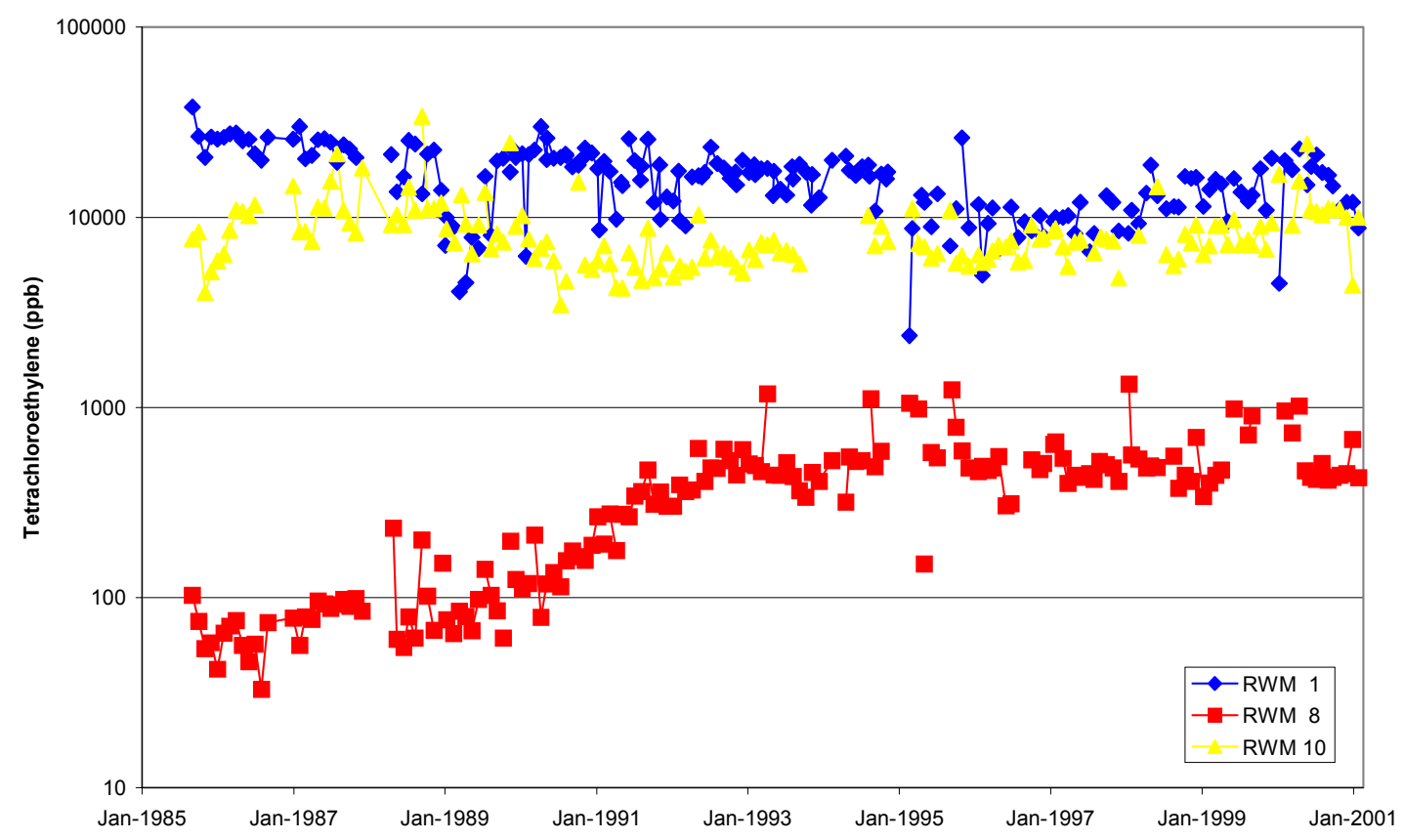

Figure 18: Tetrachloroethylene Concentrations from RWM 1, RWM 8, and RWM 10. 
Historical Trichloroethylene Concentrations from Groundwater Monitoring Wells Along Proposed DNAPL Migration Path

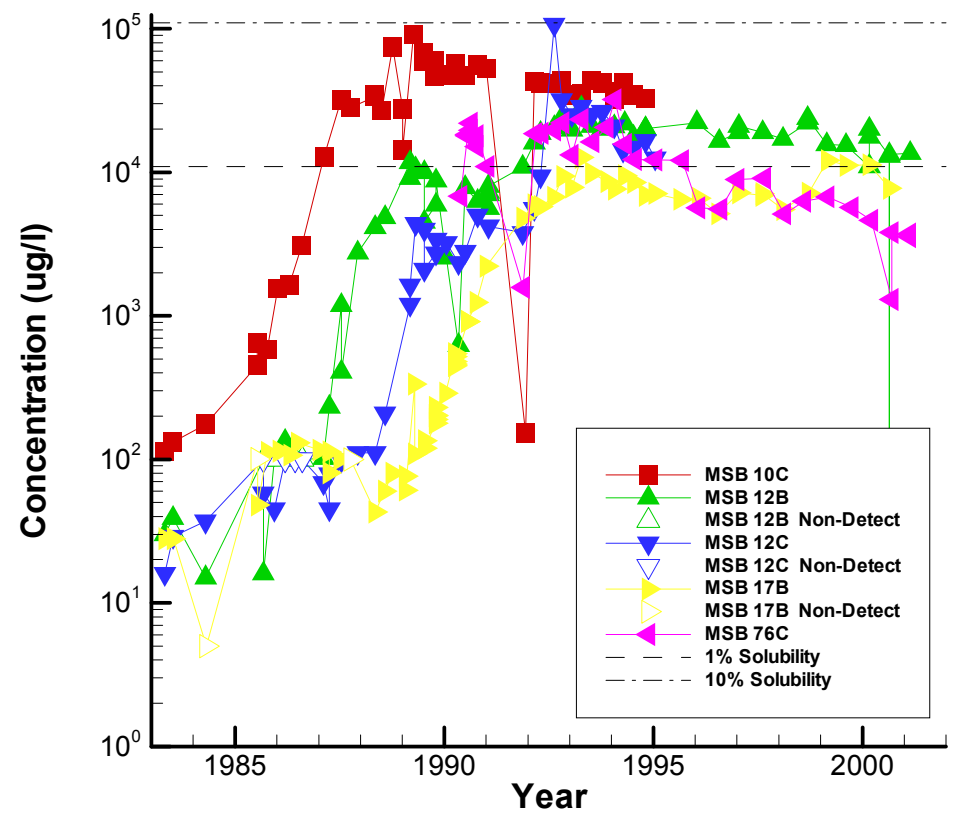

Figure 19: Historical Trichloroethylene Concentrations Along DNAPL Migration Path.

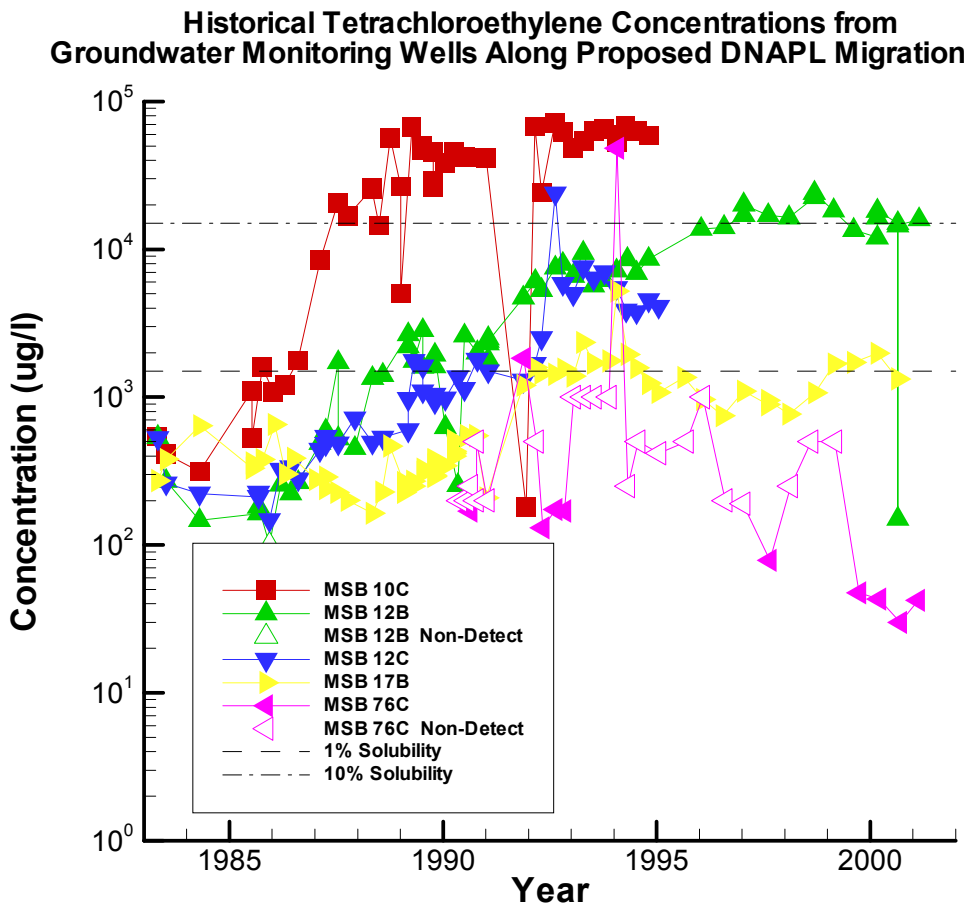

Figure 20: Historical Tetrachloroethylene Concentrations Along DNAPL Migration Path. 
Trichloroethylene and Tetrachloroethylene Concentrations from RWM-8



Figure 21: Observed and Simulated Trichloroethylene and Tetrachloroethylene Concentrations for Recovery Well RWM-8. 
Table 3: Volume Estimates For Each of the Proposed Treatment Areas Illustrated in Figure 6.

\begin{tabular}{|c|c|c|c|c|}
\hline & Zone I & Zone IIa & Zone IIIa & Zone IIb/IIIb \\
\hline 325-ft Clay & $2,088.78$ & - & - & - \\
\hline 300-ft Clay & $58,275.58$ & - & - & - \\
\hline 270-ft Clay & $156,922.39$ & - & - & - \\
\hline $\begin{array}{l}\text { M-Area } \\
\text { Aquifer }\end{array}$ & - & $79,722.47$ & $298,763.03$ & $3,469,100.54$ \\
\hline Green Clay & - & $57,445.60$ & $214,952.23$ & $2,307,978.60$ \\
\hline $\begin{array}{l}\text { Lost Lake } \\
\text { Aquifer }\end{array}$ & - & $<151,197.47$ & $<552,423.05$ & - \\
\hline $\begin{array}{c}\text { Crouch Branch } \\
\text { Upper Clay }\end{array}$ & - & - & - & - \\
\hline $\begin{array}{c}\text { Crouch Branch } \\
\text { Middle Sand }\end{array}$ & - & - & - & - \\
\hline
\end{tabular}

(Volume Estimates Are Presented in cubic yards)

Table 4: Treatment Zones and Strategraphic Intervals Associated with the Maximum Volume Scenario (Volume 6,143,474.59 cubic yards).

\begin{tabular}{|c|rrrrr|}
\hline & Zone I & Zone IIa & Zone IIIa & Zone IIb/IIIb \\
\hline 325-ft Clay & $2,088.78$ & - & - & - \\
300-ft Clay & $58,275.58$ & - & - & - \\
270-ft Clay & $156,922.39$ & - & - & - \\
M-Area & - & $79,722.47$ & $298,763.03$ & $3,469,100.54$ \\
Aquifer & - & $57,445.60$ & $214,952.23$ & $2,307,978.60$ \\
Green Clay & - & $151,197.47$ & $<552,423.05$ & \\
Lost Lake & - & - & - & \\
Aquifer & - & - & - & \\
Crouch Branch & - & & & \\
Upper Clay & - & - & & \\
Crouch Branch & - & & & \\
Middle Sand & - & & & & \\
\hline
\end{tabular}

(Volume Estimates Are Presented in cubic yards) 
Table 5: Treatment Zones and Strategraphic Intervals Associated with the Minimum Volume Scenario (Volume 156,922.39 cubic yards).

\begin{tabular}{|c|c|c|c|c|}
\hline & Zone I & Zone IIa & Zone IIIa & Zone IIb/IIIb \\
\hline 325-ft Clay & $2,088.78$ & - & - & - \\
\hline 300-ft Clay & $58,275.58$ & - & - & - \\
\hline 270-ft Clay & $156,922.39$ & - & - & - \\
\hline $\begin{array}{l}\text { M-Area } \\
\text { Aquifer }\end{array}$ & - & $79,722.47$ & $298,763.03$ & $3,469,100.54$ \\
\hline Green Clay & - & $57,445.60$ & $214,952.23$ & $2,307,978.60$ \\
\hline $\begin{array}{l}\text { Lost Lake } \\
\text { Aquifer }\end{array}$ & - & $<151,197.47$ & $<552,423.05$ & - \\
\hline $\begin{array}{c}\text { Crouch Branch } \\
\text { Upper Clay }\end{array}$ & - & - & - & - \\
\hline $\begin{array}{c}\text { Crouch Branch } \\
\text { Middle Sand }\end{array}$ & - & - & - & - \\
\hline
\end{tabular}

(Volume Estimates Are Presented in cubic yards)

Table 6: Treatment Zones and Strategraphic Intervals Associated with the Strategic Volume Scenario (Volume 294,090.46 cubic yards)

\begin{tabular}{|c|rrrrr|}
\hline & Zone I & Zone IIa & Zone IIIa & Zone IIb/IIIb \\
\hline 325-ft Clay & $2,088.78$ & - & - & - \\
300-ft Clay & $58,275.58$ & - & - & - \\
270-ft Clay & $156,922.39$ & - & - & - \\
M-Area & - & $79,722.47$ & $298,763.03$ & $3,469,100.54$ \\
Aquifer & - & $57,445.60$ & $214,952.23$ & $2,307,978.60$ \\
Green Clay & - & $<151,197.47$ & $<552,423.05$ & \\
Lost Lake & - & - & - & \\
Aquifer & - & - & - & \\
Crouch Branch & - & - & & \\
Upper Clay & - & - & & \\
Crouch Branch & - & & & \\
Middle Sand & & & - & \\
\hline
\end{tabular}

(Volume Estimates Are Presented in cubic yards) 
WSRC-TR-2001-00198

\section{References:}

Cohen, R. M. and J. W. Mercer (1993). DNAPL Site Evaluation. Boca Raton, Florida 33431, CRC Press Inc.

Colven, W. P., J. B. Pickett and C. F. Muska (1984). Closure Plan for the M-Area Settling Basin and Vicinity at the Savannah River Plant.Technical Report DPSPU 84-11-11. September 30, 1984. Savannah River Plant, Aiken, South Carolina 29808.

Domenico, P. A. and F. W. Schwartz (1998). Physical and Chemical Hydrogeology, 2nd Edition. New York, New York, John Wiley \& Sons.

Eddy-Dilek, C. A., B. D. Riha, D. G. Jackson, J. Rossabi and J. Consort (1998). DNAPL Source Zone Characterization of Launch Complex 34, Cape Canaveral Air Station, Florida.Technical Report WSRC-TR-99-00024. December 23, 1998. Westinghouse Savannah River Company, Aiken, South Carolina 29808.

Fetter, C. W. (1994). Applied Hydrogeology. Upper Saddle River, New Jersey 07458, PrenticeHall Inc.

Hollod, G. J. (1982). Physical and Chemical Characterization of the M-Area Settling Basin.Technical Report DPST-82-722. September 1982. Savannah River Laboratory, E. I. duPont de Nemours \& Company, Aiken, South Carolina 29808.

Hollod, G. J., I. W. Marine, H. W. Bledose and J. P. Ryan (1982). Metals and Organics in the Soil Beneath the M-Area Settling Basin.Technical Report DPST-71-721. July 1982. Savannah River Laboratory, E. I. duPont de Nemours \& Company, Aiken, South Carolina 29808.

Jackson, D. G. and S. E. Aleman (1995). Three Dimensional Zone of Capture Analyis for the A/M Area (U).Technical Report WSRC-RP-95-00843. May 30, 1995. Westinghouse Savannah River Company, Aiken, South Carolina 29808.

Jackson, D. G., W. K. Hyde, J. Rossabi and B. D. Riha (1999). Characterization Activities to Determine the Extent of DNAPL in the Vadose Zone at the A-014 Outfall of A/M Area (U).Technical Report WSRC-RP-99-00569. December 31, 1999. Westinghouse Savannah River Company, Aiken, South Carolina 29808.

Jackson, D. G., T. Payne, B. B. Looney and J. Rossabi (1996). Estimating the Extent and Thickness of DNAPL within the A/M Area of the Savannah River Site (U).Technical Report WSRC-RP-96-00574. December 20, 1996. Westinghouse Savannah River Company, Aiken, South Carolina 29808.

Jarosch, T. R., D. G. Jackson, J. Rossabi, B. D. Riha, J. J. Kupar and R. S. Van Pelt (1997). Extent of A/M Area Vadose Zone Contamination, Monitoring, and Corrective Action (U).Technical Report WSRC-RP-97-00109. March, 1997. Westinghouse Savannah River Company, Aiken, South Carolina 29808.

Jerome, K. M., B. B. Looney and J. Wilson (1998). Field Demonstration on In-Situ Fenton's DEstruction of DNAPLs. Physical, Chemical, and Thermal Technologies: Remediation of Chlorinated and Recalcitrant Compounds (C1-5). G. B. Wickramanayake and R. E. Hinchee. Columbus, Ohio 43201, Battelle Press: 353-358. 
WSRC-TR-2001-00198

Jerome, K. M., B. D. Riha and B. B. Looney (1997). Final Report for Demonstration of In-Situ Oxidation of DNAPL Using Geo-Cleanse Technology.Technical Report WSRC-TR-9700283. September 19, 1997. Westinghouse Savannah River Company, Aiken, South Carolina.

Looney, B. B., J. Rossabi and D. M. Tuck (1992). Assessing DNAPL Contamination, A/M-Area, Savannah River Site: Phase I Results (U).Technical Report WSRC-RP-92-01302. Westinghouse Savannah River Company, Aiken, South Carolina 29808.

Marine, I. W. and H. Bledose (1984). Supplemental technical summary M-Area groundwater investigationDPSTD-84-0112. Savannah River Laboratory, E. I. duPont de Nemours \& Company, Aiken, South Carolina 29808.

Pankow, J. A. and J. A. Cherry (1996). Dense Chlorinated Solvents and other DNAPLs in Groundwater. Portland, Oregon 91399, Waterloo Press.

Parker, W. H., A. D. Smits, M. K. Harris, D. G. Jackson and K. L. Hawkins (1999). Baseline Mapping Study of the Steed Pond Aquifer and Vadose Zone Beneath A/M Area, Savannah River Site, Aiken, South Carolina (U).Technical Report WSRC-TR-99-00295. August, 1999. Westinghouse Savannah River Company, Aiken, South Carolina 29808.

Riha, B. D., D. G. Jackson, W. K. Hyde, B. B. Looney and J. Rossabi (2001). Vadose Zone Remediation Assesement: M-Area Process Sewer Soil Vapor Extraction Units 782-5M, 782-7M, and 782-8M.Technical Report WSRC-TR-2001-00077. February, 2001. Westinghouse Savannah River Company, Aiken, South Carolina 29808.

Rossabi, J., B. B. Looney, C. A. Eddy-Dilek, B. D. Riha and D. G. Jackson (2000). DNAPL site characterization: The evolving conceptual model and toolbox approach. Treating dense nonaqueous-phase liquids (DNAPLs) : remediation of chlorinated and recalcitrant compounds (C2-2). G. B. Wickramanayake, A. R. Gavaskar and N. Gupta. Columbus, OH, Battelle Press: 41-48.

Smits, A. D., M. K. Harris, D. G. Jackson and K. L. Hawkins (1998). Baseline Mapping Study of the Steed Pond Aquifer and Crouch Branch Confining Unit Beneath A/M Area, Savannah River Site, Aiken, South Carolina (U).Technical Report WSRC-TR-98-00357. September, 1998. Westinghouse Savannah River Company, Aiken, South Carolina 29808.

Vangelas, K. M. (2000). Summary and Status of DNAPL Characterization and Remediation Activities in the A/M Area, Savannah River Site.Technical Report WSRC-RP-200100171. November 2000. Westinghouse Savananh River Comapny, Aiken, South Carolina 29808. 
Appendix A: Brief History of A/M Area DNAPL Characterization 
WSRC-TR-2001-00198

\section{Historical Information through FY 96}

Historical A/M-Area data related to DNAPL is reported and interpreted in several technical reports and in the RCRA permit and related documents. The primary topical references from this period are Assessing DNAPL Contamination, A/M-Area, Savannah River Site: Phase I Results (Looney, Rossabi et al. 1992) and Estimating the Thickness of DNAPL within the A/M-Area of the Savannah River Site (Jackson, Payne et al. 1996). These reports discuss and present available information and the DNAPL implications and interpretation. In the 1992 report, Looney et al., reviewed process use and evaluated previous monitoring well data and soil core data with regard to potential DNAPL target areas. The investigators also performed a variety of screening activities, including, geophysical and caliper logs in existing wells, detailed analysis of collected DNAPL phases, a structure contour evaluation of the green clay, and additional activities. Important data generated for the report included a cone penetrometer study of lithology in the vicinity of the M-Area Settling Basin. The report also relied on sediment concentrations and vertical cross sections previously generated by Gordon et al. (1982), Marine and Bledsoe (1984), Pickett (1985) and the RCRA Part B permit.

The 1996 report significantly extended this evaluation using a detailed time trend analysis for each monitoring well in the vicinity of potential DNAPL sources, additional interpretation related to the structure of critical clay layers in the vicinity of these sources, and a mathematical analysis of potential migration pathways. The two reports clarified the nature and distribution of DNAPL near the M-Area Settling Basin (the largest A/M-Area source) and provided indications of DNAPL behavior near the A-014 Outfall and other suspect areas. Based on the information, three pilot scale DNAPL targeted treatments were deployed. These included six phase heating and radiofrequency heating along the former process sewer line near the settling basin, and insitu oxidation using Fenton's reagent in a DNAPL accumulation zone west of the M-Area Settling Basin. As discussed below, the pre-test and post-test data from these activities provide additional information related to DNAPL behavior and distribution.

\section{FY97 through FY99}

Specific follow-on characterization activities were conducted in FY97 through FY99 to refine our knowledge of the extent of the VOC plume and the spatial distribution of DNAPL within the plume. The following activities were conducted and the documents in which the results were reported are listed below.

Characterization of the Vadose Zone at the A-014 Outfall using CPT based technologies as reported in "Characterization Activities to Determine the Extent of DNAPL in the Vadose Zone at the A-014 Outfall of A/M-Area (U), WSRC-RP-99-00569.

Characterization of a potential DNAPL transport pathway before and after a demonstration of a DNAPL remediation technology using rotosonic drilling as reported in "Final Report for Demonstration of In Situ Oxidation of DNAPL Using Geo-Cleanse Technology (U)", WSRCTR-97-00283.

Characterization below the water table at known DNAPL source areas using rotosonic drilling to complete 13 soil borings with soil plug samples as reported in "A/M-Area DNAPL Characterization Report for Cores Collected in FY97 and 1Q98 and 2Q98 (U)", WSRC-TR-9800296. 
WSRC-TR-2001-00198

Characterization adjacent to and below the M-Area Settling Basin using rotosonic vertical and angle drilling to determine the spatial distribution of DNAPL adjacent to and below the basin as report in "A/M-Area DNAPL Characterization Report for Cores Collected in 2Q99", WSRC-TR99-00468.

\section{FY00}

Characterization activities in FY00 included depth discrete soil sampling of borings drilled using the rotosonic method, soil gas samples and lithology data gathered using cone penetrometer techniques. The depth discrete soil samples were collected adjacent and below the M-Area Settling Basin and adjacent to the A-014 outfall. Depth discrete soil samples were also collected in FY00 to support the Lynntech demonstration and the Dynamic Underground Stripping (DUS) deployment at the $321 \mathrm{M}$ solvent storage tank. The results of those sampling events are reported in Vangelas (2001, 2000b and 2000c).

At the M-Area Settling Basin (in FY 2000) one vertical boring was drilled adjacent to the western corner of the basin and one angle boring was drilled from the western corner of the basin towards the center of the basin. At the A-014 outfall two angle borings were drilled running parallel to the outfall stream. A third boring was drilled vertically above the location where PCE concentrations identified in one angle boring indicated the presence of DNAPL. All borings were sampled from surface to the top of the Green Clay (Vangelas 2001).

The sampling to support the Lynntech demonstration Vangelas et al. (2000b).involved collecting soil samples using a Geo-Probe after the Lynntech soil ozone treatment demonstration was completed. The purpose was to determine the amount of PCE and TCE remaining in the soil to allow the Lynntech personnel to evaluate the effectiveness of the ozone in the destruction of DNAPL. This demonstration was conducted adjacent to the 321-M Solvent Storage Tank concrete pad. The sampling to support the DUS deployment Vangelas et al. (2000a) involved collecting soil samples at four locations from mud rotary drilled soil borings. The purpose of this sampling was to provide additional data soil conditions prior to deployment of steam flushing. Soil plug samples were collected from surface to the top of the Green Clay at approximately 20 foot intervals. 